\title{
vB_PaeM_MIJ3, a Novel Jumbo Phage Infecting Pseudomonas aeruginosa, Possesses Unusual Genomic Features
}

\author{
Mohammed Imam 1,2, Bandar Alrashid ${ }^{3,4}$, Faizal Patel ${ }^{3}$, Ahmed S. A. Dowah $^{3}$, \\ Nathan Brown ${ }^{3}$, Andrew Millard ${ }^{3}$, Martha R. J. Clokie ${ }^{3}$ and Edouard E. Galyov ${ }^{3 *}$ \\ 1 Department of Respiratory Sciences, College of Life Sciences, University of Leicester, Leicester, United Kingdom, \\ ${ }^{2}$ Laboratory Department, University Medical Center, Umm Al-Qura University, Mecca, Saudi Arabia, ${ }^{3}$ Department \\ of Genetics and Genome Biology, College of Life Sciences, University of Leicester, Leicester, United Kingdom, ${ }^{4}$ King Faisal \\ Specialist Hospital and Research Centre, Riyadh, Saudi Arabia
}

\section{OPEN ACCESS}

Edited by:

Robert Czajkowski, University of Gdańsk, Poland

Reviewed by:

Adelaide Almeida, University of Aveiro, Portuga

Shuai Le,

Army Medical University, China

*Correspondence:

Edouard E. Galyov eg98@/eicester.ac.uk

Specialty section This article was submitted to Virology,

a section of the journal Frontiers in Microbiology

Received: 13 September 2019 Accepted: 13 November 2019 Published: 28 November 2019

Citation:

Imam M, Alrashid B, Patel F Dowah ASA, Brown N, Millard A, Clokie MRJ and Galyov EE (2019) VB_PaeM_MIJ3, a Novel Jumbo Phage Infecting Pseudomonas aeruginosa, Possesses Unusual

Genomic Features.

Front. Microbiol. 10:2772. doi: 10.3389/fmicb.2019.02772
Phages are the most abundant biological entity on Earth. There are many variants in phage virion sizes, morphology, and genome sizes. Large virion sized phages, with genome sizes greater than $200 \mathrm{kbp}$ have been identified and termed as Jumbo phages. These phages exhibit certain characteristics that have not been reported in phages with smaller genomes. In this work, a jumbo phage named MIJ3 (vB_PaeM_MIJ3) that infects Pseudomonas aeruginosa PAO1 was isolated from an equine livery yard in Leicestershire, United Kingdom. The genome and biological characteristics of this phage have been investigated. MIJ3 is a Myovirus with multiple long tail fibers. Assessment of the host range of MIJ3 revealed that it has the ability to infect many clinical isolates of $P$. aeruginosa. Bioinformatics analysis of the phage genome indicated that MIJ3 is closely related to the Pseudomonas phage, PA5oct. MIJ3 possesses several unusual features that are either rarely present in other phages or have not yet been reported. In particular, MIJ3 encodes a FtsH-like protein, and a putative lysidine synthase, TilS. These two proteins have not been reported in phages. MlJ3 also possesses a split DNA polymerase B with a novel intein. Of particular interest, unlike other jumbo phages infecting Pseudomonas spp., MIJ3 lacks the genetic elements required for the formation of the phage nucleus, which was believed to be conserved across jumbo Pseudomonas phages.

Keywords: bacteriophages, Pseudomonas aeruginosa, jumbo phages, intein, host range analysis, antibiotic resistance, phylogenetic analysis

\section{INTRODUCTION}

Pseudomonas aeruginosa is a widespread Gram-negative bacterium. It is an opportunistic pathogen and is the major cause of nosocomial infection with significant mortality rates. P. aeruginosa causes a wide variety of infections, ranging from self-limiting skin infections to life-threatening pneumonia and septicemia. Between January 2018 and January 2019, a total of 4,543 septicemia cases caused by $P$. aeruginosa were reported in England alone (Public Health England, 2019). The severity of $P$. aeruginosa infections is particularly high and problematic in immunocompromised 
patients with conditions such as cystic fibrosis (CF) and chronic obstructive pulmonary disease (COPD) (Gonçalves-deAlbuquerque et al., 2016). In fact, chronic pulmonary infections with $P$. aeruginosa is a major cause of death in CF patients (Ashish et al., 2012). With increasing rates of multiple-drug resistance (MDR) $P$. aeruginosa infections, phages are suggested as an alternative treatment solution, or to be combined with antibiotic, to treat bacterial infections (Krylov et al., 2015).

Bacterial viruses, bacteriophages (or phages), are the most abundant microorganisms in the environment (Suttle, 2005). Strikingly, it is estimated that almost half of the bacterial cells present in the environment are killed by phages every day (Potera, 2013). Phages are generally found in abundance where their hosts are found, and as such they are commonly found and isolated from environments such as freshwater, seawater, and animal manure (Clokie et al., 2011; Chaturongakul and Ounjai, 2015). The most common habitats for $P$. aeruginosa are water, soil, plants, and animals (Chatterjee et al., 2017). These sources are natural environments from which Pseudomonasspecific phages can be isolated, as phages coexist with their host cells (Shaburova et al., 2006; Krylov, 2014). There is strong evidence supporting the effectiveness of phage therapy in the treatment of lung infections associated with $P$. aeruginosa (Waters et al., 2017). Recent work by Cafora et al. (2019) shows the effectivity of phages against $P$. aeruginosa infection in a model of zebrafish with CF.

Phages vary in their size, morphology, and genomes. Examples of common and well-studied phages are the T4 Myovirus, which has a genome size of $168,903 \mathrm{bp}$, the T7 Podovirus which has a genome size of 39,937 bp, and the T5 Siphovirus which has a genome size of $121,752 \mathrm{bp}$. Phages with larger genome sizes are grouped as either jumbo or mega phages.

Phages with genome sizes over $500 \mathrm{~kb}$ are grouped collectively as megaphages (Devoto et al., 2019). To date, only 15 megaphages have been found, all of which infect bacteria from the Prevotella genus (Devoto et al., 2019). All of the megaphages were identified genomically from the analysis of viral metagenomics data; these phages have not been physically isolated yet. On the other hand, phages with genome sizes $>200 \mathrm{~kb}$, but $<500 \mathrm{~kb}$, have been termed jumbo phages (Yuan and Gao, 2017). Over 150 jumbo phage genomes have been deposited into the EBI and NCBI databases. The majority of them infect different Gram-negative bacteria, of which includes species from Escherichia, Aeromonas, Caulobacter, Erwinia, Pseudomonas, Vibrio, and Salmonella. Only six jumbo phages infecting Gram-positive bacteria have been characterized; all of which infect Bacillus species. A full list of megaphages and jumbo phages described to date, can be found in Supplementary Table 1.

At the time of this manuscript's submission, the largest jumbo phages described are: Bacillus virus $G$ with a genome size of 497,513 bp (Donelli et al., 1975), Agrobacterium phage Atu_ph07 with a genome size of 490,380 bp (Attai et al., 2018), and Salicola phage SCTP-2 with a genome size of $440,001 \mathrm{bp}$. According to the latest review on jumbo phages, the largest Pseudomonas phage is the $P$. chlororaphis phage $201 \varphi 2-1$, with a 316,674 bp genome size (Thomas et al., 2008). All reported Pseudomonas jumbo phages are listed in Table $\mathbf{1 .}$
TABLE 1 | A full list of jumbo phages infecting Pseudomonas species, including phage MIJ3 (red).

\begin{tabular}{llccc}
\hline & Accession & Phage name & Classification & $\begin{array}{c}\text { Genome } \\
\text { length (bp) }\end{array}$ \\
\hline 1 & NC_010821 & 201phi2-1 & Phikzvirus & 316,674 \\
2 & HQ630627 & PhiPA3 & Phikzvirus & 309,208 \\
3 & MF042360 & Phabio & Phikzvirus & 309,157 \\
4 & LR588166 & MIJ3 & Unclassified & 288,170 \\
5 & MK797984 & PA5oct & Unclassified & 287,182 \\
6 & JN627160 & OBP & Unclassified & 284,757 \\
7 & NC_017972 & Lu11 & Unclassified & 280,538 \\
8 & AF399011 & phiKZ & Phikzvirus & 280,334 \\
9 & MF805716 & SL2 & Phikzvirus & 279,696 \\
10 & KU521356 & KTN4 & Phikzvirus & 279,593 \\
11 & AP019418 & PA02 & Phikzvirus & 279,095 \\
12 & MF063068 & Noxifer & Noxifervirus & 278,136 \\
13 & JX233784 & PA7 & Phikzvirus & 266,743 \\
14 & KF147891 & PaBG & Unclassified & 258,139 \\
15 & AJ697969 & EL & Elvirus & 211,215 \\
\hline
\end{tabular}

Because of their large genome size, jumbo phages encode many hypothetical proteins with unknown functions, in addition to encoding homologs of bacterial proteins, which might be an indication for phage-bacterial evolutionary events. Unlike other well-studied phages such as T4, jumbo phages lack recognizable modular genome characteristics that help to classify this group of phages. Phylogenetic analysis of the essential phage elements such as the major capsid proteins, terminases, and other proteins, revealed the presence of a new and phylogenetically related group within the jumbo phages, these have been termed the "Rak2like viruses" (Šimoliūnas et al., 2013). This group encompasses eight phages: CBB, vB_CsaM_GAP32, BF, vB_KleM-Rak2, K641, 121Q, vB_Eco_slurp01, PBECO4, and Atu_ph07 (Attai et al., 2018). Most of the other characterized jumbo phages belong to different taxonomic families and orders, making it a challenging task to determine the similarities between them. Therefore, the terms "megaphages" and "jumbo phages" are umbrella terms which refer to the size of phages rather than an inherent set of qualities.

Jumbo phages exhibit characteristics that are rarely, or not at all observed in phages with smaller genomes. However, most Pseudomonas jumbo phages share some lifestyle features. In particular, it has been shown by Chaikeeratisak et al. (2017a) that the genomes of Pseudomonas jumbo phages (201phi21, phiKZ, and phiPA3) encode conserved proteins responsible for the formation of the phage nucleus, and tubulin spindle in the host bacterium during phage replication. A nucleuslike structure is formed in the cytoplasm of infected bacteria after phage DNA injection. It surrounds the phage DNA and separates it from the host cytoplasm, allowing the replication and transcription of phage DNA to occur inside the "phage nucleus" (Chaikeeratisak et al., 2017b). It has been suggested that the presence of such a nucleus-like structure is a conserved characteristic feature of all jumbo phages infecting Pseudomonas species (Chaikeeratisak et al., 2017a). 
In this article, we report the isolation and characterization of a novel $P$. aeruginosa jumbo phage designated MIJ3 (vB_PaeM_MIJ3) with a genome size of 288,170 bp. We describe the MIJ3 phage morphology, pattern of infectivity, genomics characteristics, and proteomic identification of some of the major structural components. We also discuss how phage MIJ3 is a unique phage representing a novel phage species and genus.

\section{MATERIALS AND METHODS}

\section{Bacterial Strains and Culture Conditions}

Pseudomonas aeruginosa strain PAO1 was used for phage isolation and propagation. Cells were cultivated in LB (LuriaBertani) broth at $37^{\circ} \mathrm{C}$ with shaking at $120 \mathrm{RPM}$. The bacterial strains used for the phage MIJ3 host range analysis were 44 Liverpool Epidemic Strains (LES) (Winstanley et al., 2009), 12 strains isolated from patients with ventilator-associated pneumonia (VSP) at the Leicester Royal Infirmary (Freestone et al., 2012), a strain isolated from a COPD patient (Source: Dr. Christopher Turkington) and 2 lab strains $P$. aeruginosa PAO1 and PA14 (Table 2).

\section{Isolation of Phage MIJ3}

Phage MIJ3 was isolated from a manure run-off in an equine livery yard, on which sheep are also kept, in Leicestershire. Due to the nature of the sample, a series of filtration steps were performed, starting initially with a $25 \mathrm{~mm}$ filter, down to filters with $0.22 \mu \mathrm{m}$ pore sizes, this in order to remove bacteria. The filtered sample was screened for the presence of culturable phages using the plaque assay technique (Bonilla et al., 2016). Briefly, a mixture containing $300 \mu \mathrm{l}$ of mid-log bacterial culture, $100 \mu \mathrm{l}$ of the filtered sample, and $7 \mathrm{ml}$ of LB top agar ( $0.7 \%)$ was poured on to a $\mathrm{LB}$ base plate and incubated overnight at $37^{\circ} \mathrm{C}$ to allow for the formation of phage plaques.

\section{Plaque Purification and Phage Propagation}

A single plaque was picked and resuspended in $500 \mu \mathrm{l}$ of $\mathrm{SM}$ buffer $\left(5.8 \mathrm{~g} \mathrm{NaCl}, 2.0 \mathrm{~g} \mathrm{MgSO}_{4} \cdot 7 \mathrm{H}_{2} \mathrm{O}, 50 \mathrm{ml} 1 \mathrm{M}\right.$ Tris-HCl, $\mathrm{pH} 7.4$, in $1 \mathrm{~L}$ of $\mathrm{dH}_{2} \mathrm{O}$ ). After incubating for

TABLE 2 | A summary list of $P$. aeruginosa strains used in this study (a full detailed list of strains is presented in Supplementary Table 2).

\begin{tabular}{llc}
\hline Strain & Source & References \\
\hline PAO1 & Lab strain & Lab strain \\
PA14 & Lab strain & Lab strain \\
LES strains 1-40 & Cystic fibrosis patients & Winstanley et al., 2009 \\
LES400 & Cystic fibrosis patient & \\
LES431 & Cystic fibrosis patient & \\
LESB58 & Cystic fibrosis patient & \\
LESB65 & Cystic fibrosis patient & \\
LRI strains 1-12 & Ventilator-associated & Freestone et al., 2012 \\
& pneumonia patients & \\
COPD & COPD patient & Dr. Christopher Turkington
\end{tabular}

$60 \mathrm{~min}$ at $37^{\circ} \mathrm{C}$, the solution was centrifuged, and the supernatant was filtered through $0.22 \mu \mathrm{m}$ pore size filters. To produce a homogenous phage stock, seven rounds of single plaque purification were performed. Thereafter, the propagation of the phage was performed by preparing a plate lysate. The lysate was centrifuged, and the supernatant was filtered through a $0.22 \mu \mathrm{m}$ pore size filter to remove bacterial cells (Bonilla et al., 2016). The titer of propagated phage was measured by the spot test as described in Mazzocco et al. (2009) with modifications. Briefly, phage lysate was serially diluted (12-fold) in SM buffer, and $10 \mu \mathrm{l}$ of each dilution was spotted on a double-layer LB plate. The bottom layer contains $1 \%(\mathrm{w} / \mathrm{v}) \mathrm{LB}$ agar and the top layer is composed of $0.5 \%(\mathrm{w} / \mathrm{v}) \mathrm{LB}$ agar mixed with $100 \mu \mathrm{l}$ of exponentially growing $P$. aeruginosa culture. The plates were all dried for $25 \mathrm{~min}$ in a laminar flow hood (ASTEC, MicroFlow) before it was incubated at $37^{\circ} \mathrm{C}$ for $18 \mathrm{~h}$. The plaque forming unit $(\mathrm{pfu} / \mathrm{ml})$ was measured by counting the plaques in the dilution that have 3-30 countable plaques using the following calculation: Average number of plaque $\times 100 \times$ reciprocal of dilution $=\mathrm{pfu} / \mathrm{ml}$.

\section{Transmission Electron Microscopy}

Transmission electron microscopy analysis was performed according to the protocol of Ackermann (2009). Phage MIJ3 was negatively stained using $2 \%$ uranyl acetate on a carbon-coated grid, and visualized using the JEM 1400 transmission electron microscope (JEOL Co., Japan) with an accelerating voltage of $80 \mathrm{kV}$ (Leicester, United Kingdom). Phage particle dimensions were measured using Image J version $1.49 \mathrm{o}^{1}$ in relation with the scale bar generated from the microscope.

\section{Adsorption Assay}

To determine the time required for phage MIJ3 to attach to its host $P$. aeruginosa PAO1, an adsorption assay was performed according to the protocol mentioned by Kropinski (2009). Briefly, $0.95 \mathrm{ml}$ of LB broth, and three drops of chloroform were added to 12 labeled tubes and placed on ice to chill for $10 \mathrm{~min}$. A midlog phase bacterial culture was diluted to $10 \mathrm{ml}$ to an $\mathrm{OD}_{600}$ of 0.2 . Two flasks (A and C) were filled with $9 \mathrm{ml}$ of bacterial culture and LB broth, respectively, and placed in a shaking water bath $(60 \mathrm{rpm})$ at $37^{\circ} \mathrm{C}$. At $0 \mathrm{~min}, 1 \mathrm{ml}$ of the warmed phage being tested at a titer of $1 \times 10^{5} \mathrm{pfu} / \mathrm{ml}$ was added. Immediately, $1 \mathrm{ml}$ of phage was added to the control flask (C). Aliquots of $0.05 \mathrm{ml}$ from flask (A) were removed to the chilled labeled tubes every $1 \mathrm{~min}$ and mixed vigorously. Plaque assays were performed using test tubes containing $0.1 \mathrm{ml}$ of chloroform in order to measure the phage titration.

\section{One-Step Growth Curve}

To define the latent period and the average burst size of MIJ3, the one-step growth experiment was performed as described previously (Hyman and Abedon, 2009). Briefly, $9 \mathrm{ml}$ of bacterial culture at an $\mathrm{OD}_{600}$ of 0.2 , and $90 \mu \mathrm{l}$ of phage MIJ3 at a concentration of $10^{8}$ (MOI of 0.01 ) were mixed and incubated

\footnotetext{
${ }^{1}$ https://imagej.nih.gov/ij/
} 
for $6 \mathrm{~min}$ at $37^{\circ} \mathrm{C}$. The mixture was centrifuged at $4,500 \mathrm{rpm}$ for $5 \mathrm{~min}$ at $4^{\circ} \mathrm{C}$ to pellet the cells. The resultant pellet was washed with $5 \mathrm{ml}$ of fresh LB broth and centrifuged again. The pellet was re-suspended in $10 \mathrm{ml}$ of $\mathrm{LB}$ broth, and the mixture was incubated at $37^{\circ} \mathrm{C}$. Aliquots of $1 \mathrm{ml}$ of the mixture were collected at 15 -min intervals for $2 \mathrm{~h}$. Phages at each time points, including time point 0 , were diluted and enumerated via the plaque assay. The $\mathrm{pfu} / \mathrm{ml}$ was calculated and plotted against time. The period of latency was observed, and phage burst size was calculated from the plotted curve.

\section{Killing Assay}

To assess the killing activity of phage MIJ3 on the host, $P$. aeruginosa $\mathrm{PAO} 1$ growing in $\mathrm{LB}$ was infected with $\mathrm{MIJ} 3$ in different MOIs as described in Chen et al. (2018). Briefly, $30 \mu \mathrm{l}$ of phage at concentrations of $10^{10}, 10^{9}$, and $10^{8} \mathrm{PFU} / \mathrm{ml}$ were mixed separately with $270 \mu \mathrm{l}$ of mid-log bacteria at concentration of $10^{8} \mathrm{CFU} / \mathrm{ml}$ to make MOIs of 10,1 , and 0.1 , respectively. The mixtures were incubated at $37^{\circ} \mathrm{C}$ and the bacterial growth was then monitored by measuring optical densities at $\mathrm{OD}_{600}$ for $3 \mathrm{~h}$. Bacterial culture without phages was used as a control. The data were obtained from three independent experiments.

\section{Thermal and pH Stability of Phage MIJ3}

The stability of phage MIJ3 in different temperatures was investigated. Aliquots of phage MIJ3 were incubated at 40, 50, 60, $70,80,90$, and $100^{\circ} \mathrm{C}$ for $1 \mathrm{~h}$ before enumerating the surviving phages by spot test. Phage stability under different $\mathrm{pH}$ conditions was carried out according to Ahmadi et al. (2016). SM buffer was prepared with different $\mathrm{pH}$ values, ranging from 1 to 10 using either $1 \mathrm{M} \mathrm{HCL}$ or $1 \mathrm{M} \mathrm{NaOH}$. MIJ3 at a concentration of $10^{11}$ was added to each $\mathrm{pH}$ solution, and the solutions were incubated for an hour before quantifying the number of phages in each solution.

\section{Host Range Analysis}

To determine the host range of MIJ3, $10 \mu \mathrm{l}$ of phage lysate was spotted on to a lawn of each of the tested $P$. aeruginosa strains isolated from patients with CF or COPD. The appearance of the spot was observed after an overnight incubation of the plates at $37^{\circ} \mathrm{C}$, and scored as (1) for complete lysis, (2) for turbid and weak lysis, and (3) for no lysis. Strains marked as 1 or 2 were analyzed further by spot testing to confirm any plaque formation.

\section{Phage DNA Extraction}

The DNA from phage MIJ3 was extracted by using the phenolchloroform-isoamyl alcohol method as described in Nale et al. (2015). Phage lysate was treated with DNase and RNase to remove free DNA. To degrade the phage capsid, EDTA, proteinase $\mathrm{K}$, and SDS were added to the lysate, and the mixture was incubated for an hour at $55^{\circ} \mathrm{C}$. Phenol-chloroform-isoamyl alcohol (25:24:1) was added to the mixture at a $1: 1$ ratio and vortexed. The resulting sample was centrifuged at $21,000 \times g$ for $15 \mathrm{~min}$. The top aqueous layer was collected and treated with 1 volume of $3 \mathrm{M}$ sodium acetate, and 2 volumes of ice-cold absolute ethanol, and then incubated for $3 \mathrm{~h}$ at $-20^{\circ} \mathrm{C}$ and, centrifuged at $21,000 \times g$ for $15 \mathrm{~min}$. The DNA pellet was washed with $75 \%$ ethanol and re-suspended in $\mathrm{upH}_{2} \mathrm{O}$. The DNA concentration was measured using the Qubit fluorometer (Thermo Scientific).

\section{Sequencing and Bioinformatics Analysis}

Genomic libraries of phage MIJ3 DNA were prepared using Illumina's TruSeq ${ }^{\circledR}$ DNA Library Prep Kit (300 bp, FC121-2003, Illumina), and whole genome sequencing was carried out using the MiSeq ${ }^{\circledR}$ FGx system (Illumina). The resulting FASTQ files were assembled with Megahit version 1.2.1 (Li et al., 2015, 2016). The genome was sequenced to an average coverage depth of $35.38 \times$. The resultant single phage contig was annotated with Prokka version 1.12, using the protein model databases HAMAP, VOG and Bacteria Viruses. In addition to this, manual gene prediction using all of the complete viral genomes available within the NCBI database and the European Nucleotide Archive (ENA) was performed (Seemann, 2014). Another method of annotation was performed using the Rapid Annotation using Subsystem Technology (RAST) pipeline as described previously (McNair et al., 2018).

An MIJ3 genome map was generated and visualized using Artemis version 17.0.1 (Carver et al., 2011). For phylogenetic analysis, amino acid sequences of phage core proteins such as the major capsid and terminase were checked for similarities in the NCBI database using BLASTp tool. Moreover, phages with homology to the amino acid sequences of these MIJ3 proteins were selected to generate phylogenetic trees using the MEGA7 software (Molecular Evolutionary Genetics Analysis) version 7.0 (Kumar et al., 2016). Selected amino acid sequences of phage proteins (major capsid protein and terminase) were aligned using ClustalW, and the resulting alignment file was used to create phylogenetic trees by the neighbor-joining method (Saitou and Nei, 1987). Genome comparison was analyzed using EasyFig version 2.2.3 (Sullivan et al., 2011).

To determine genome-to-genome distance of phage MIJ3 and other phages in the databases, VICTOR online tool was used $^{2}$. All pairwise comparisons of the amino acid sequences were conducted using the Genome-BLAST Distance Phylogeny (GBDP) method (Meier-Kolthoff et al., 2013) under settings recommended for prokaryotic viruses (Meier-Kolthoff and Göker, 2017). The resulting intergenomic distances were used to infer a balanced minimum evolution tree with branch support via FASTME including SPR post-processing (Lefort et al., 2015). Branch support was inferred from 100 pseudo-bootstrap replicates each. Trees were rooted at the midpoint (Farris, 1972). Taxon boundaries at the species, genus, and family level were estimated with the OPTSIL program (Göker et al., 2009), the recommended clustering thresholds (Meier-Kolthoff and Göker, 2017), and an F-value (fraction of links required for cluster fusion) of 0.5 (Meier-Kolthoff et al., 2014).

\footnotetext{
${ }^{2}$ https://ggdc.dsmz.de/victor.php
} 


\section{Accession Numbers}

Reads for phage MIJ3 were deposited to the ENA at the European Bioinformatics Institute (EBI) under project accession number PRJEB32093. The taxon ID of MIJ3 is 2567864, and the phage genome was submitted under accession number LR588166.

\section{Phage Purification Using $\mathrm{CIM}^{\circledR}$ Monoliths}

Phage MIJ3 was purified using an anion-exchange chromatography column as described in Vandenheuvel et al. (2018) with some modifications. Briefly, $5 \mathrm{ml}$ of the phage lysate $\left(1.5 \times 10^{11} \mathrm{pfu} / \mathrm{ml}\right)$ was dialyzed overnight at $4^{\circ} \mathrm{C}$ against a loading buffer $\left(4 \mathrm{~g} \mathrm{MgSO}_{4} \cdot 6 \mathrm{H}_{2} \mathrm{O}, 50 \mathrm{ml}\right.$ of $1 \mathrm{M}$ Tris- $\mathrm{HCl}$, pH 7.5, ultra-pure $\mathrm{H}_{2} \mathrm{O}$ up to $1 \mathrm{~L}$ ). The CIMmultus ${ }^{\mathrm{TM}}$ QA1 Advanced Composite Column was attached to the AKTA ${ }^{\mathrm{TM}}$ FPLC $^{\text {TM }}$ system before washing with the loading buffer. The elution buffer $\left[116.9 \mathrm{~g}(2 \mathrm{M}) \mathrm{NaCl}, 4 \mathrm{~g} \mathrm{MgSO} 4 \cdot 6 \mathrm{H}_{2} \mathrm{O}, 50 \mathrm{ml}\right.$ of $1 \mathrm{M}$ Tris- $\mathrm{HCl}, \mathrm{pH} 7.5$, ultra-pure $\mathrm{H}_{2} \mathrm{O}$ up to $1 \mathrm{~L}$ ] was added to the phage lysate, and the mixture was loaded on to the column. The fractions were analyzed using the UNICORN ${ }^{\mathrm{TM}}$ and GraphPad Prism software. Phage titers in each fraction were determined by spot tests (Supplementary Figure 1).

\section{Proteomics Analysis}

An aliquot of $25 \mu \mathrm{l}$ purified phage was suspended in SDS loading buffer and heated for $5 \mathrm{~min}$ at $95^{\circ} \mathrm{C}$. Then, proteins were separated using $12 \%$ SDS-PAGE gel, and stained using Coomassie stain. The major bands were extracted from the gel and analyzed by mass spectrometry (LC-MS/MS) at the Protein Nucleic Acid Chemistry Laboratory (PNACL, University of Leicester, United Kingdom), in accordance with Lavigne et al. (2009).

\section{RESULTS}

\section{Isolation of Phage MIJ3}

In an attempt to isolate novel phages capable of infecting $P$. aeruginosa, we sampled water from mixed animal manure (horse and sheep) from an equine yard. A sample of the manure runoff water was collected and analyzed for the presence of phages capable of infecting $P$. aeruginosa using spot tests. Several phage plaques were observed on the $P$. aeruginosa PAO1 lawn. Plaques with distinct morphologies were selected for further studies. A small distinct plaque (approx. $0.5 \mathrm{~mm}$ in diameter) was purified via several rounds of plaque assays. The isolated phage was designated as vB_PaeM_MIJ3 (referred to herein as MIJ3), according to the phage naming criteria suggested by Adriaenssens and Brister (2017).

\section{Morphological Characteristics of Phage MIJ3}

Transmission electron microscopy analysis of purified MIJ3 revealed that the phage belongs to the Myoviridae family. The average overall length of the phage from the top of the capsid to the base plate is $258 \mathrm{~nm}$, with an average head height of $130 \mathrm{~nm}$ and $118 \mathrm{~nm}$ width. The phage tail has a height of $140 \mathrm{~nm}$ and length of $28 \mathrm{~nm}$ ( $n=10$ phages) (Figure 1). MIJ3 has the

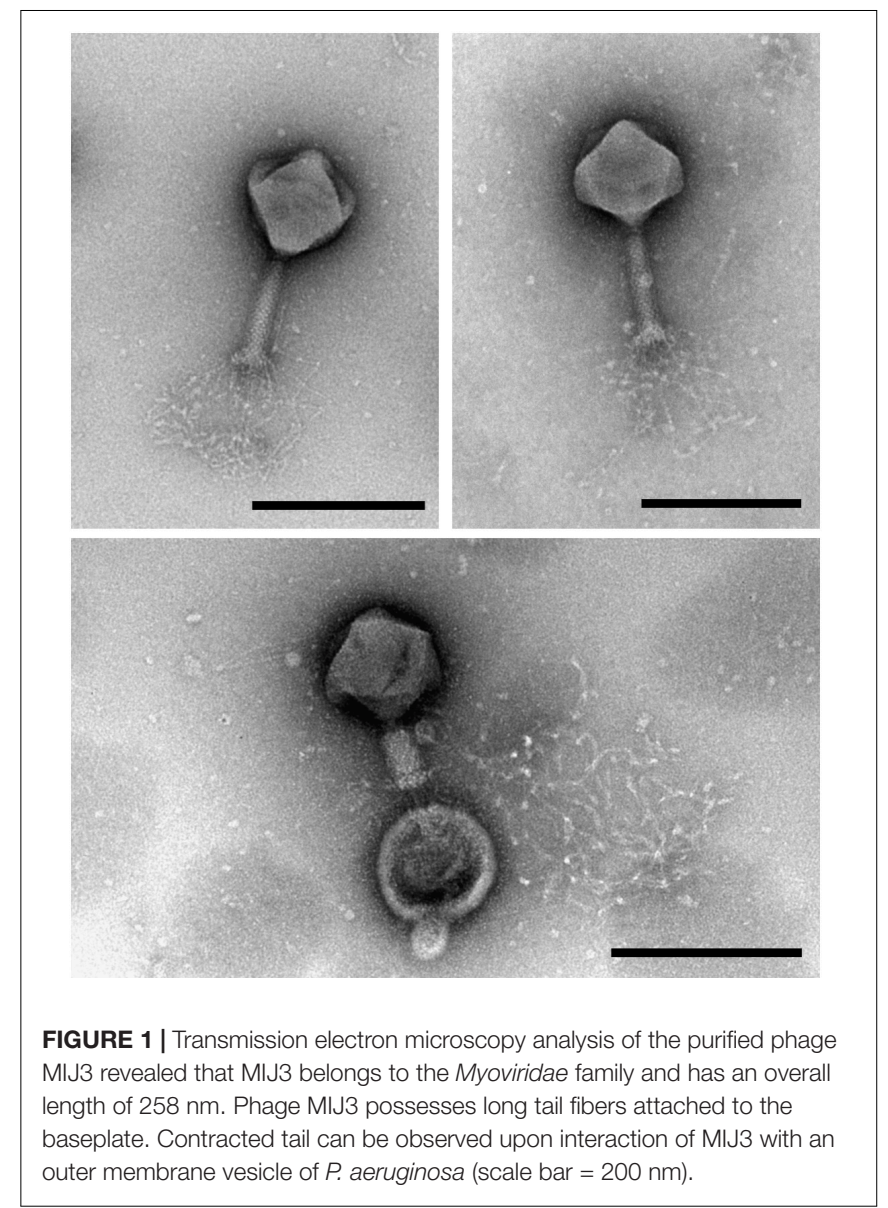

characteristic morphological features of a Myovirus morphotype A1: a classical phage head, a contractile tail with a collar, and a spiky baseplate attached to thin long kinked fibers (Figure 1).

\section{Adsorption Assay and One-Step Growth Curve}

An adsorption assay was performed to identify the rate at which phage MIJ3 adsorbs to the surface of $P$. aeruginosa PAO1. The resulted graph (Figure 2A) revealed that around $50 \%$ of the phages attach to the host cells within $6 \mathrm{~min}$, and $90 \%$ of the phages were adsorbed to host cells in $20 \mathrm{~min}$. Phage growth parameters were determined by analyzing the phage growth cycle using the one-step growth curve experiment. The latent period of MIJ3 is between 45 and $50 \mathrm{~min}$, and the burst size of one lytic cycle is approx. 68 pfu per infected cell (Figure 2B).

\section{Killing Assay}

To assess the killing activity of the phage on the host strain, $P$. aeruginosa $\mathrm{PAO} 1$ was grown in LB broth and infected with MIJ3 using different MOI values (10, 1, and 0.1), and the bacterial growth was monitored by measuring optical densities at $\mathrm{OD}_{600}$. In each case, the phage infection resulted in the inhibition of bacterial growth, which was progressively more prominent with an increase in the MOI. The lysis kinetics of MIJ3 was determined on strain PAO1. The optical density of the culture decreased at 

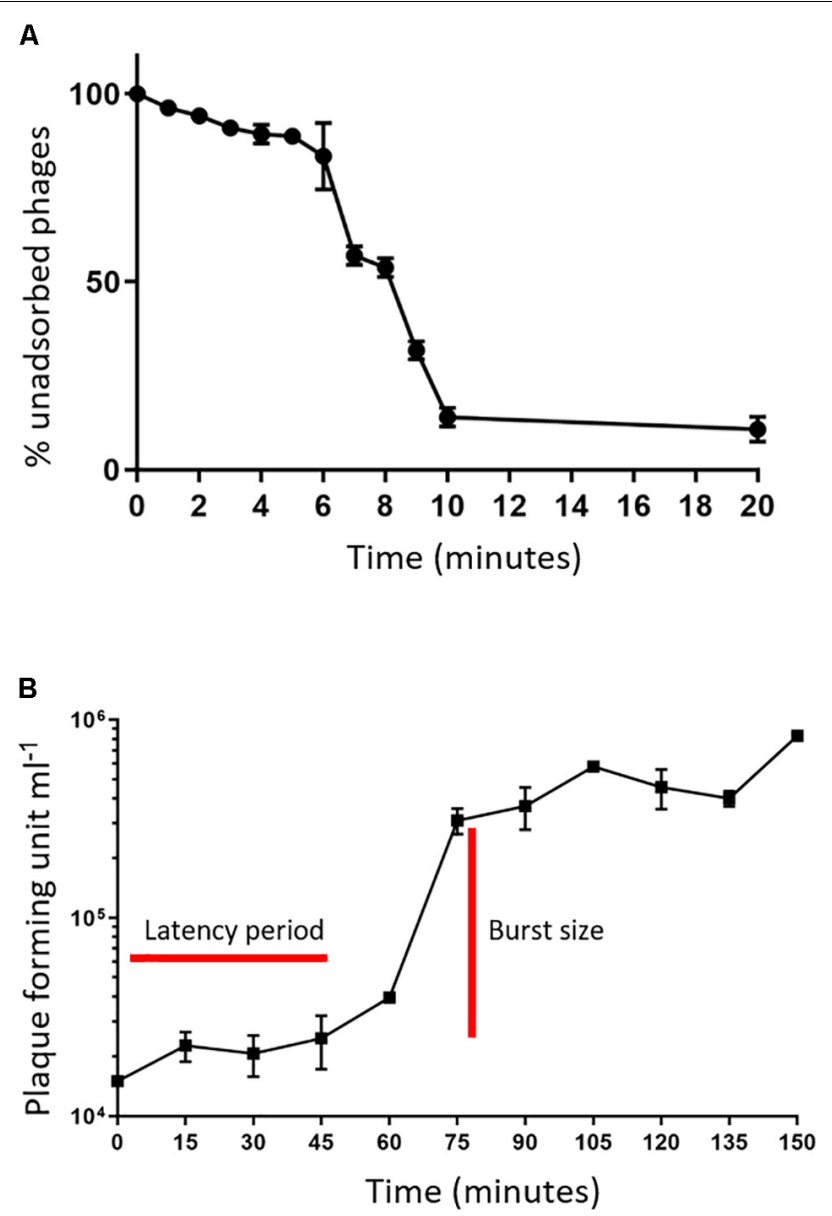

FIGURE 2 | (A) Adsorption assay of phage MIJ3 on P. aeruginosa. (B) Growth parameters of MIJ3. The latent period of MIJ3 is between 45 and $50 \mathrm{~min}$, and the burst size of one lytic cycle is 68 pfu per infected cell. Three biological replicates performed. approximately $80 \mathrm{~min}$ post-infection with all three MOI values. At a high phage titer (MOI of 10), the bacterial growth rate was reduced because of phage infection. When an equal ratio of phage to bacteria was used (MOI of 1), bacterial growth showed a slight increase after $90 \mathrm{~min}$. At a lower phage titer (MOI of 0.1), bacterial growth was higher than that observed with the cells infected at an MOI of 1 and 10, but still lower than the non-infected cells. The non-infected sample was used as a control, showing the growth of $P$. aeruginosa without adding any phage (Figure 3).

\section{Thermal and pH Stability of Phage MIJ3}

Assessing the stability of phages provides essential information for storage, transfer, and downstream experiments with the phage. Phage MIJ3 shows high stability at temperatures of 40,50 , and $60^{\circ} \mathrm{C}$, as phage titers were similar to the control $\left(4^{\circ} \mathrm{C}\right)$. After incubation for an hour at $70^{\circ} \mathrm{C}$, there was a 4 log reduction in the phage MIJ3 titer, indicating that only 1 in 10,000 phages have survived under such conditions. Very few, if any, MIJ3 phage particles were able to survive at 80, 90, and $100^{\circ} \mathrm{C}$ (Figure 4A). Phage MIJ3 appears to be stable at $\mathrm{pH}$ values from 3 to 10 . However, MIJ3 is not able to survive highly acidic $\mathrm{pH}$ values, as no phages survived testing against $\mathrm{pH}$ values of 2 and 1 (Figure 4B).

\section{Host Range of Phage MIJ3}

The host range and lytic activity of MIJ3 on different clinical strains of $P$. aeruginosa was assessed by using spot test assays. Zones of lysis were observed and scored as (1) for complete lysis, (2) for turbid and weak lysis, and (3) for no lysis. For strains that were marked as (1) or (2), the phage stock was diluted and spotted on the bacterial lawn to show that the phage was forming single plaques, and the clearing was not due to lysis from without. The results reveal that MIJ3 is able to infect, and form plaques on,

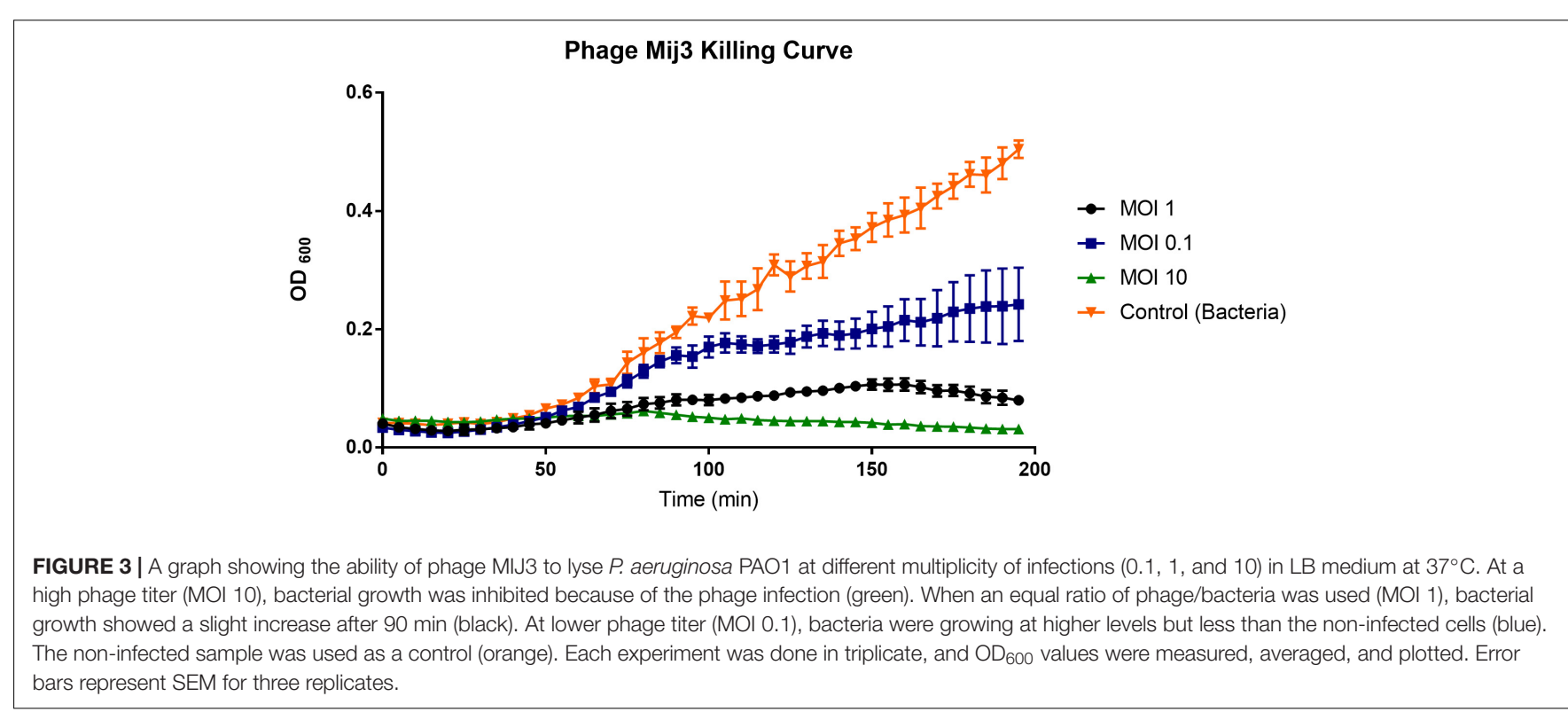




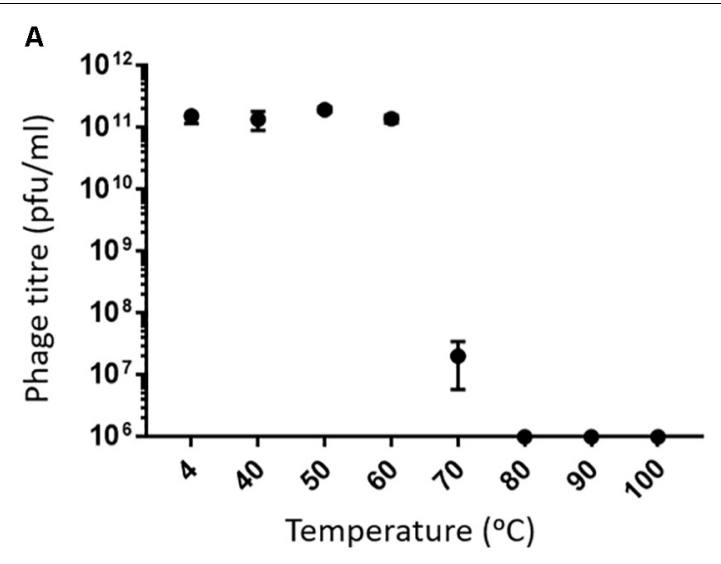

B

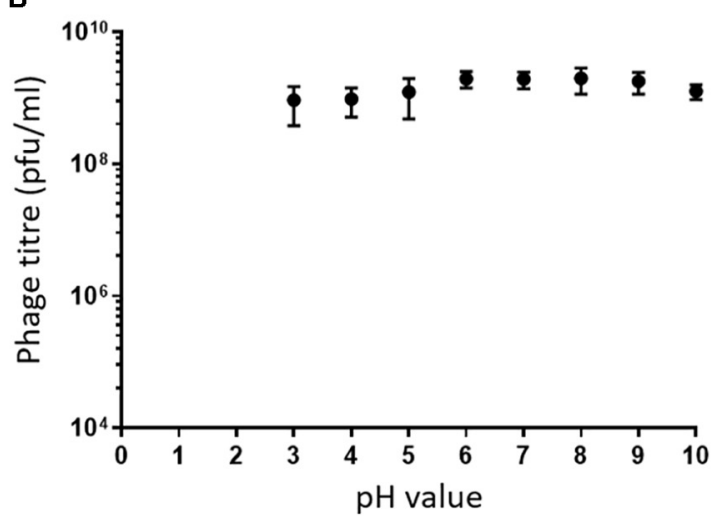

FIGURE 4 | (A) Thermal stability of MIJ3: the phage was incubated in LB medium at different temperatures for $60 \mathrm{~min}$. The phages survived at temperatures of 40,50 , and $60^{\circ} \mathrm{C}$. At $70^{\circ} \mathrm{C}$, phage concentration showed a 4-log drop. MIJ3 was not able to survive at 80,90 , and $100^{\circ} \mathrm{C}$. Error bars represent SEM for three replicates. (B) pH stability of MIJ3. The phage is highly stable at $\mathrm{pH}$ values from 3 to 10; however, no survival was observed when phages at a $\mathrm{pH}$ of 2 and 1.

multiple clinical strains of $P$. aeruginosa isolated from patients with CF or VSP (as detailed in Supplementary Table 2).

\section{MIJ3 Genome and Phylogeny Analysis}

The genome of phage MIJ3 was sequenced using the MiSeq platform, and the sequence was annotated by Prokka and RAST as described previously (Seemann, 2014; McNair et al., 2018). The phage was found to possess a large genome of $288,170 \mathrm{bp}$ and was thus classified as a jumbo phage. The average $\mathrm{G}+\mathrm{C}$ content of the genome of MIJ3 is $33.3 \%$, which is in striking contrast to that of the bacterial host (66\%). Blastn comparison of the MIJ3 sequence against the NCBI non-redundant database revealed that MIJ3 has significant similarity with one phage, a Pseudomonas phage vB_PaeM_PA5oct (98.72\% identity). This was a surprising finding as the genome size of PA5oct was previously reported to be $375 \mathrm{kbp}$ (Drulis-Kawa et al., 2014). However, the sequence deposited in the NCBI database revealed that the actual genome size of PA5oct is 287,182 bp (accession number: MK797984).
The annotation of the phage MIJ3 sequence revealed the presence of 405 predicted open-reading frames (ORFs) and 12 tRNAs (Supplementary Table 3 and Figure 5). There are 21 ORFs encoding structural components, including 5 capsid proteins (gp41, gp406, gp409, gp410, and gp411) and 6 predicted tail proteins (gp1, gp4, gp36, gp142, gp144, and gp386). In addition, 24 proteins involved in DNA replication, recombination, repair, and transcription were identified. The majority of predicted genes (328 ORFs) encode hypothetical proteins with unknown functions. The MIJ3 genome encodes 12 tRNAs located between gp228 and gp246 and arranged as tRNA-Met, tRNA-Leu, tRNA-Asn, tRNA-Thr, tRNA-Met, tRNA-Leu, tRNA-Arg, tRNA-Met, tRNA-Pro, tRNA-Gly, tRNASer, and tRNA-Ser.

Phages MIJ3 and PA5oct have $<10 \%$ ANI when compared with other phage sequences in the current databases, suggesting that they are a new species which belong to a new genus of phages that are not closely related to other phage groups. To find the location of MIJ3 in the phage continuum context, phylogenetic trees were generated for some of the predicted essential phage proteins, including the major capsid protein (Figure 6) and the terminase large subunit (Figure 7). From the assessment of phylogenetic trees, it seems that phage MIJ3 is not related to any other specific group of phages. The trees show the cluster of the newly identified group of jumbo phages called the Rak2-like phages family, which contains Xanthomonas phage XacN1 (Yoshikawa et al., 2018), Agrobacterium phage Atu_ph07 (Attai et al., 2018), Serratia phage BF (Casey et al., 2017), Enterobacteria phage vB_PcaM_CBB (Buttimer et al., 2017), Cronobacter phage vB_CsaM_GAP32 (Abbasifar et al., 2014), Klebsiella phage K64-1 (Pan et al., 2017), Escherichia phage 121Q (Ackermann and Nguyen, 1983), and Klebsiella phage vB_KleM-RaK2 (Šimoliūnas et al., 2013). Although the terminase of phage MIJ3 has similarities with RaK2-like phages, it is not considered as Rak2-like since all of these phages are over $300,000 \mathrm{bp}$, and due to the wide distance between the sequence of the major capsid protein sequence of phage MIJ3 and the Rak2like phages. Furthermore, phylogenetic analysis of the major capsid protein tree shows that other Pseudomonas jumbo phages form an outgroup according to this protein sequence and are not closely related to MIJ3.

Like other jumbo phages described to date, in addition to ORFs encoding "typical" phage proteins, the MIJ3 genome encodes for several proteins showing sequence similarity to bacterial host proteins. Several such "host-like" proteins found to be encoded in the MIJ3 genome are rare in phages, of which, two proteins not been found in any phages to date. These two proteins are homologs of the FtsH protein (ATP-dependent zinc metalloprotease) and Tils [tRNA(Ile)-lysidine synthase]. FtsH and Tils are widely conserved proteins in bacteria. FtsH, formerly known as $\mathrm{HflB}$, plays an important role in maintaining membrane integrity, cell division, and in the heat shock response (Bieniossek et al., 2006). TilS is a tRNA modification enzyme and is essential for bacterial viability (Suzuki and Miyauchi, 2010). To analyze the evolutionary relationship of the unique phage borne FtsH in phage MIJ3, and to track down the origin of this protease, a phylogenetic tree of FtsH was created as described 


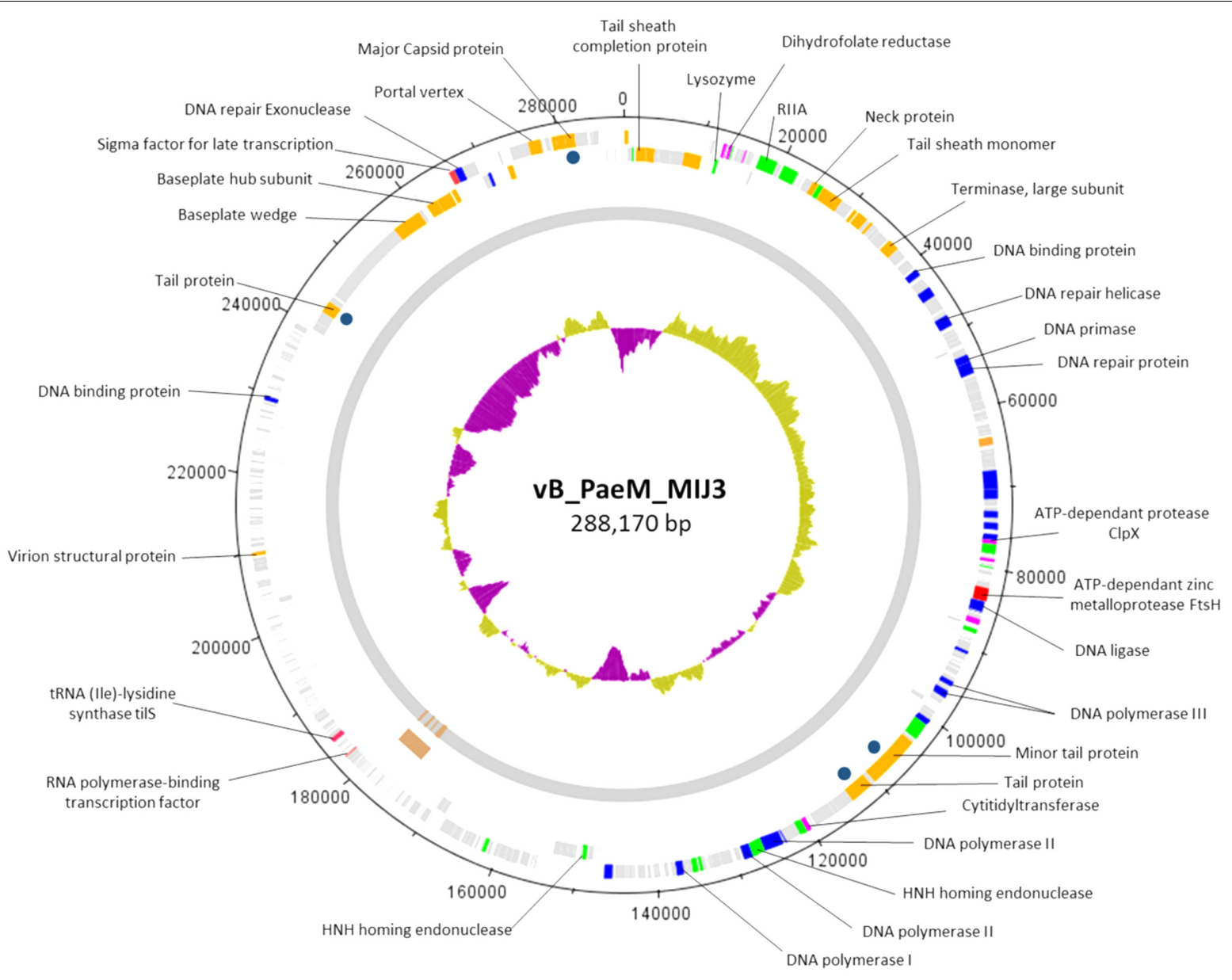

Structural proteins

DNA replication and repair
Host-phage interaction proteins

DNA transcription
tRNA
Nucleotide metabolism

Hypothetical proteins

FIGURE 5 | Circular genomic map of bacteriophage MIJ3. Phage MIJ3 possesses proteins involved in virion structure (orange), host-phage interaction (green), nucleotide metabolism (purple), DNA replication and repair (blue), and DNA transcription (pink). It also encodes host-like proteins such as FtsH (red) and tilS. There are 12 tRNAs in the genome of MIJ3 (brown). Other proteins with unknown functions are marked with gray. Dark blue dots indicate structural proteins confirmed by ESI-MS/MS. The map was generated using Artemis version 17.0.1.

previously (Figure 8). The analysis shows that the bacterial FtsH proteins are grouped separately from viral FtsH. The FtsH of phage MIJ3 has a closer relationship to the bacterial FtsH, rather than the viral FtsH.

For the same purpose, a phylogenetic tree for the Tils protein was constructed using the neighbor-joining method shows that TilS MIJ3 amino acid sequence is identical to the sequence of the uncharacterized protein in phage PA5oct. Similar to the findings from the FtsH phylogeny analysis, the TilS sequence of phage MIJ3 is a closer relative to the bacterial TilS protein rather than the viral TilS. Although the genome of $P$. aeruginosa PAO1, the bacterial host of MIJ3, encodes TilS protein, the Tils protein of MIJ3 is distantly related to the host Tils (Figure 9).
Further analysis of the annotated MIJ3's genomic data revealed another unusual feature: a putative split intein with an $\mathrm{HNH}$ homing endonuclease family (orf154) within the genes encoding the DNA polymerase B (orfs153 and 155) (Figure 10). Inteins are mobile self-splicing elements intervening the host protein sequence, and they are excised post-translation through a process known as protein splicing (Perler, 2005). They are often associated with the homing endonuclease domain to mediate this genetic transfer (Dassa et al., 2009). Intein motifs can be identified by conserved residues that are involved in protein splicing (Pietrokovski, 1994; Perler et al., 1997). In phage MIJ3, the intein motif blocks were identified in the N-terminal splicing region: block A (SVDGSTILNTSL), block N2 (TIEELFNV), block B (NKVIVTEDHSIMV), and block N4 


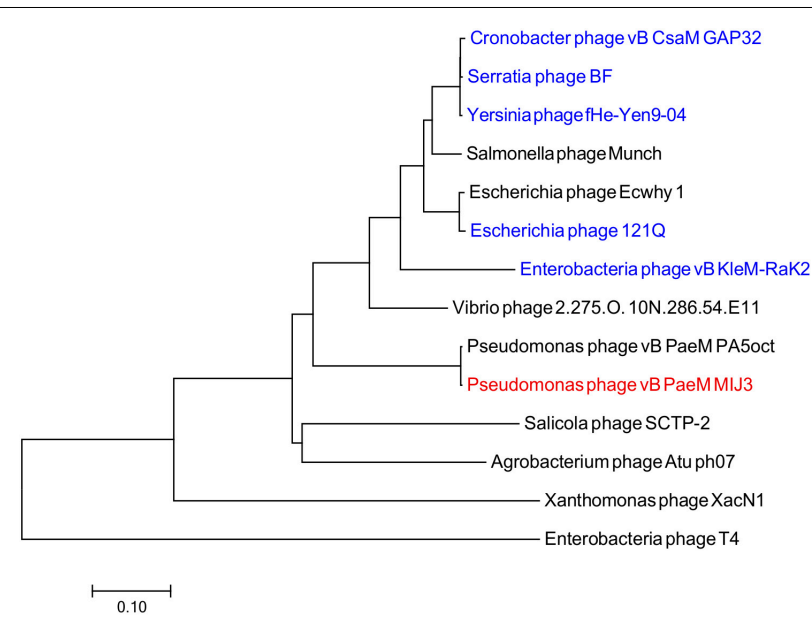

FIGURE 6 | Phylogenetic tree comparing the major capsid protein of phage MIJ3 (red) with its corresponding in other jumbo phages, including Rak2-like phages (blue). Phages were selected as they share homology with the amino acid sequences of the major capsid using Blastp. Phage T4 was selected as an outgroup phage that is not closely related to the corresponding sequence of MlJ3. The evolutionary history was inferred using the neighbor-joining method and the tree was constructed using MEGA7.

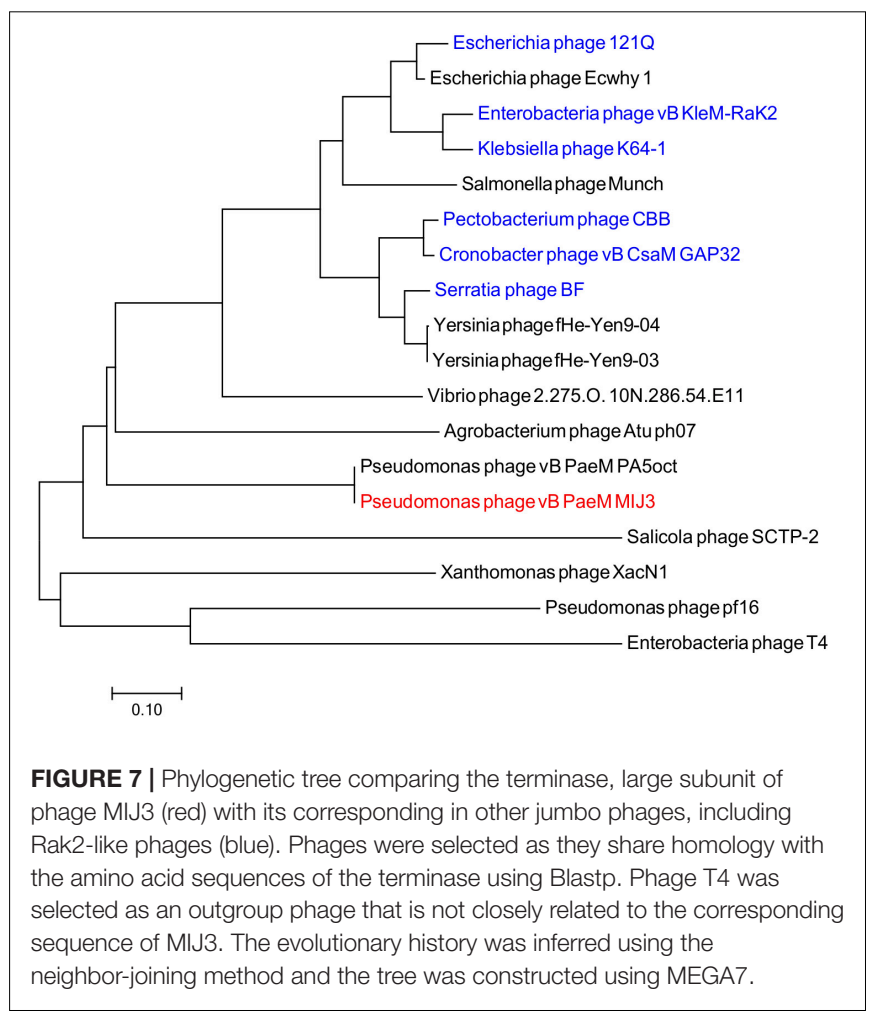

(LLEVKPTDLTDSDIIL); and in the C-terminal splicing region: block F (VYDIGMKNPDNPYFF) and block G (GNNILVHNS). Bioinformatic analysis of the protein-splicing sequence element of the phage revealed that the putative MIJ3 split intein shares a similarity with the mini-intein present in the gene encoding PolB in another jumbo phage, the Salicola phage SCTP-2 (Figure 10).

\section{Phage Purification Using $\mathrm{CIM}^{\circledR}$ Monoliths and Proteomics Analysis}

Phage MIJ3 was purified by using an anion-exchange chromatography column as previously described in the section "Materials and Methods" (Figure 11A). Eluted fragments under the phage peak were pooled, and the phage titers were calculated using spot tests. The purified MIJ3 titer was $4 \times 10^{10} \mathrm{pfu} / \mathrm{ml}$, indicating that the phage titer decreased by $1 \log$, compared to the titer of the non-purified phage, which was $1.2 \times 10^{11} \mathrm{pfu} / \mathrm{ml}$. The purified MIJ3 virions were separated by SDS-PAGE, and several major protein bands were analyzed by MS. Four structural proteins were identified by LC-MS/MS, including the major (gp144) and the minor tail proteins (gp142), a tail fiber protein (gp386), and the major capsid protein (gp411) (Figure 11B). These proteins were confirmed by the genome annotation of the phage in relation to the sizes of their amino acid sequences in the gel and in the annotation information.

\section{DISCUSSION}

Phages are abundant in different environments but very large phages are not commonly isolated. They could be removed during the filtration process due to their large virion sizes, or because of their limited mobility on semi-solid plates (Serwer et al., 2007). Genomes of jumbo phages and megaphages encode a number of hypothetical proteins with unknown functions, and their biological features are understudied and not found in small phages. Jumbo phages have more genes encoding DNA replication and metabolism such as DNA polymerase and RNA polymerase in addition to genes responsible for translation (Yuan and Gao, 2017). Abundance of these genes indicates less dependency on the host in addition to wider host ranges. More studies are expected to be conducted to reveal more features of these phages.

Phage MIJ3, described here, is an interesting representative of jumbo phages for numerous reasons. The phage is effective against clinical strains of $P$. aeruginosa that were isolated from patients with CF or COPD. This suggests that MIJ3 can potentially be used for further phage therapy trials, especially for infections with multi-drug resistant $P$. aeruginosa. It can also be added to the existing phage cocktails for more effective outcomes. There is the need to test phage MIJ3 with other $P$. aeruginosa phages against more strains to expand the therapeutic applicability of jumbo phages. Other jumbo phages such as phiPA3, PA5oct, phiKZ, SL2, KTN4, PA02, PA7, and PaBG also have the ability to infect a wide range of clinical isolates of $P$. aeruginosa (Mesyanzhinov et al., 2002; Monson et al., 2011; Sykilinda et al., 2014; Latz et al., 2017). These phages were isolated from different sources all of which are, respectively, different to each other, examples include sewage, mudflat, lake water, and manure, indicating the diversity of available sources of phages with promising therapeutic potential.

Pseudomonas aeruginosa strains are associated with mucus formations and are able to surround themselves with exopolysaccharides, which are alginic acids, providing resistance 


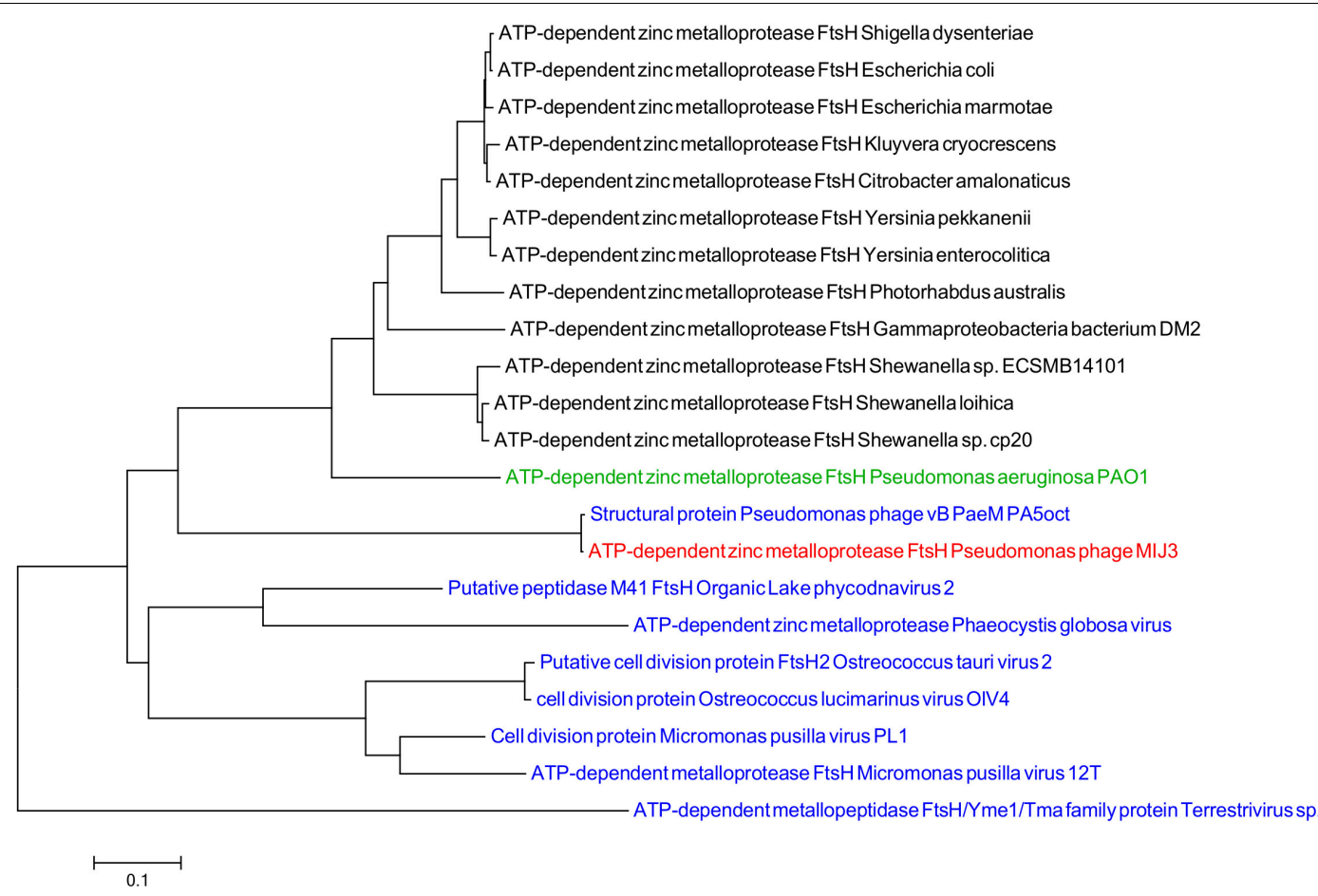

FIGURE 8 | Phylogenetic tree of FtsH based on the amino acid sequence of phage MIJ3 and the most similar sequences in the database. It shows the FtsH of MIJ3 (red), the most similar amino acid sequences in viruses (blue), and bacteria (black) including P. aeruginosa PAOI, the bacterial host of MIJ3 (green).

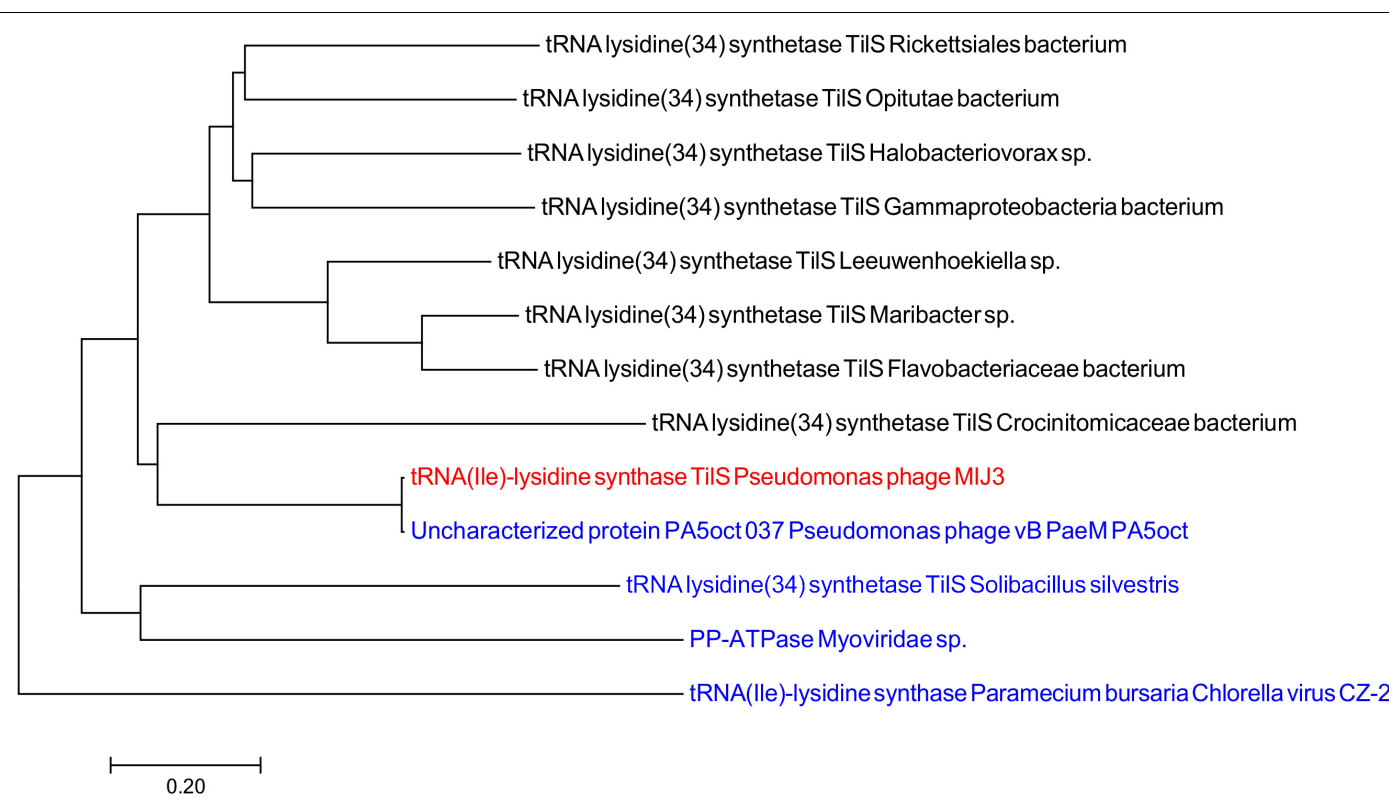

FIGURE 9 | Phylogenetic tree of TilS based on the amino acid sequence of phage MIJ3 and the most similar sequences in the database. It shows the TilS of MIJ3 (red), the most similar TilS amino acid sequences in viruses (blue), and bacteria (black).

to antibiotics and immune cells, especially in CF patients (Glonti et al., 2010; Morello et al., 2011). Phages have showed promising effects in treating infections caused by multi-drug resistant $P$. aeruginosa isolated from patients with $\mathrm{CF}$ in vivo and in vitro
(Furfaro et al., 2018). Therefore, phage MIJ3 can potentially be used in phage therapy against Pseudomonas infections. In addition, phage endolysins and peptidoglycan-degrading enzymes from phages phiKZ and EL have been previously 


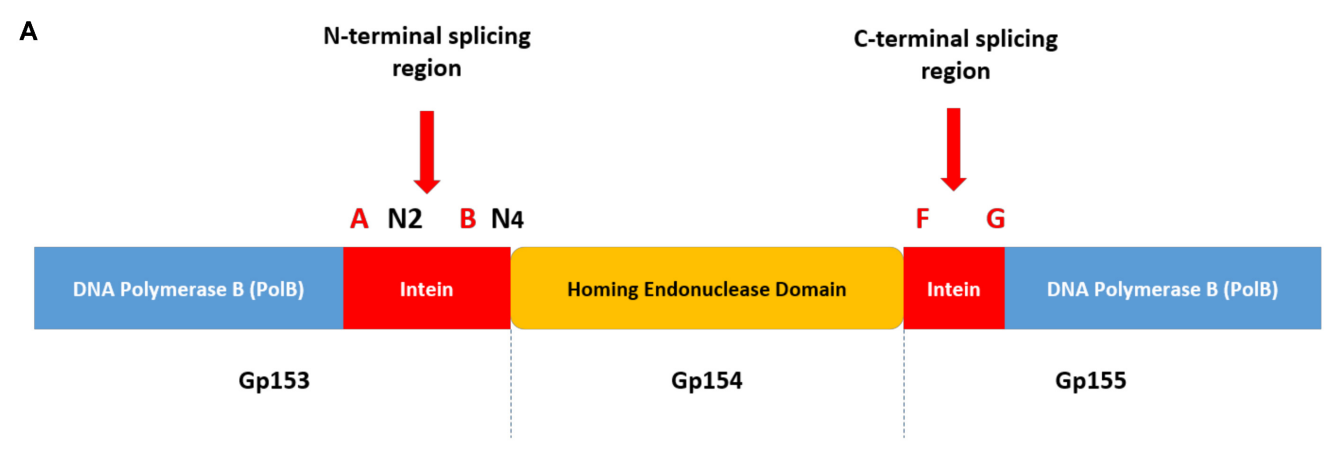

B
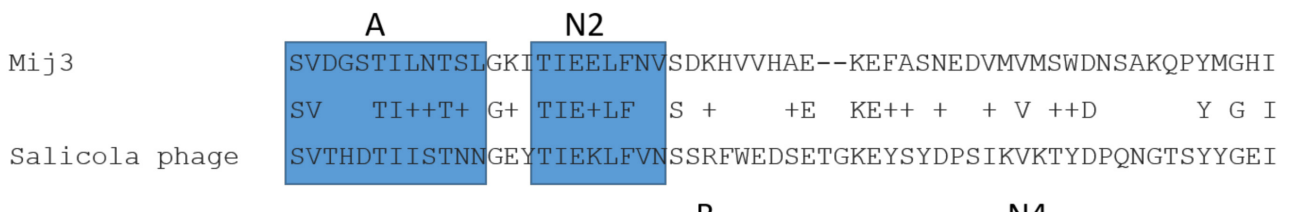

$\operatorname{Mij} 3$

Salicola phage

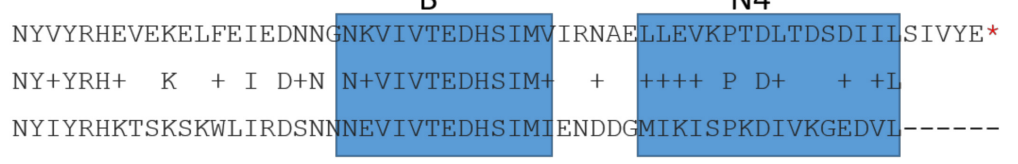

$\operatorname{Mij} 3$

MHNLTKHLLGVFSAKTEDEEYNSAKRALEELNKNIKERDPNKFNVSLGKVSKVTNLGKKK

$+T \quad V \quad E D \quad V$ LG

Salicola phage

---ITVKCGEVLKCSIED------------------------IVWLGYFD--------N

C

Mij3
Salicola phage

F G

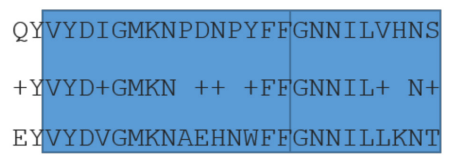

FIGURE 10 | The presence of intein in MIJ3. (A) A diagram illustrating the location of the intein and its conserved motifs in the genome of MIJ3 jumbo phage. (B) N-terminal splicing region sequence alignment between inteins inserted in the PoIB of MIJ3 and the Salicola phage SCTP-2 with the identified intein motifs highlighted as blocks A, N2, B, and N4. (C) C-terminal splicing region sequence alignment of the intein in both phages with the identified intein motifs are highlighted as blocks $\mathrm{F}$ and $\mathrm{G}$.

tested as potential antibacterial agents against Pseudomonas infections (Briers et al., 2007). Similar proteins from MIJ3 could be investigated and used for the same purpose.

The physical and chemical stability of phage MIJ3 was determined to provide more information with regards to phage storage, transport, and potential applications. MIJ3 is stable at temperatures ranging from 4 to $60^{\circ} \mathrm{C}$; however, only approximately 1 in 10,000 phage particles survived when incubated at $70^{\circ} \mathrm{C}$ for $1 \mathrm{~h}$, and it was inactivated when incubated at 80,90 , and $100^{\circ} \mathrm{C}$. More than $90 \%$ of $\mathrm{MIJ} 3$ phage survived at $\mathrm{pH}$ values ranging from $\mathrm{pH} 10$ to 3 but, couldn't survive at $\mathrm{pH} 1$ and 2 . It has been suggested that tailed phages are more resistant to adverse conditions such as temperature change and $\mathrm{pH}$ (Ackermann et al., 2004). For therapeutic purposes, phages are required to maintain stability in a wide range of temperatures and $\mathrm{pH}$, to resist changes in environmental and ambient condition, and MIJ3 appears to satisfy these criteria. The ability to withstand the aforementioned conditions provides valuable information as to whether MIJ3 would be able to survive downstream processing steps such as encapsulation or spray drying, especially if MIJ3 was to be used for therapeutic purposes.

The genomic sequence of MIJ3 and PA5oct have greater than 95\% suggesting that they represent a new phage species according to the main species demarcation criterion (Adriaenssens and Brister, 2017). These phages are unique as their genome sequences share ANI of $<1 \%$ with other phages in the database. Members of the same genus share a high degree of nucleic acid similarity ( $>50 \%$ ) with others, along with factors such as genome length, average and percentage of coding sequencing, number of tRNA, and the presence of certain signature genes in member viruses (Adriaenssens and Brister, 2017). 
A

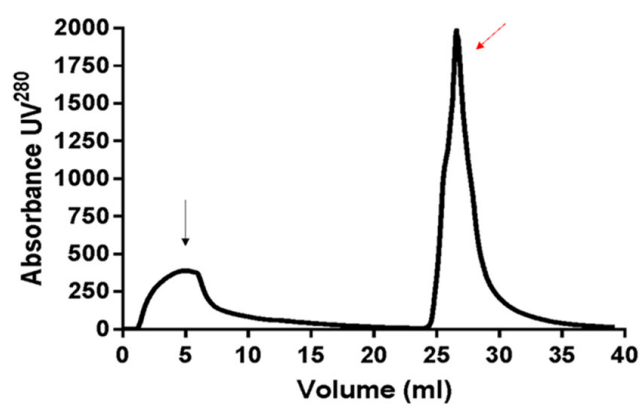

B

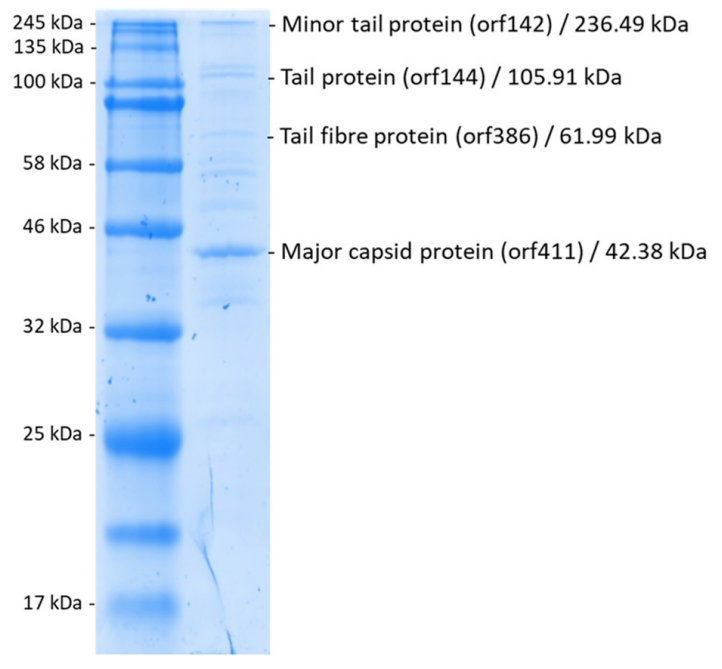

FIGURE 11 | (A) Linear gradient of MIJ3 purification using a DEAE column. The black arrow indicates the flow-through and the red arrow indicates the peak that corresponds with the presence of phage MIJ3. (B) Proteomic analysis of phage MIJ3 particles. Proteins of purified phage particles $(\mathbf{B})$ were separated in $12 \%(\mathrm{wt} / \mathrm{vol})$ polyacrylamide gel by SDS-PAGE and stained with Coomassie brilliant blue. The protein bands were subjected to LC-MS/MS analysis. On the right are the descriptions of the genes, their deduced molecular sizes based on the ORF sequences, and their possible functions. Positions of size markers are shown on the left (A).
Analysis of the genome-to-genome phylogeny of phage MIJ3 and other phages (Figure 12), and the phylogenetic trees of the major capsid protein and terminase (large subunit) (Figures 6, 7), shows that MIJ3 has a distant relation with other phages including GAP32, K64-1, Rak2, PBECO 4, and 121Q. According to the ICTV database, these phages are classified into different genera. Phages K64-1 and Rak2 are members of the Alcyoneusvirus genus, phages $121 \mathrm{Q}$ and PBECO4 belong to the Asteriusvirus genus, and phage GAP32 belongs to the Mimasvirus genus. In addition to VICTOR analysis, this suggests that MIJ3 and PA5oct represent a new genus.

The phage MIJ3 genome encodes proteins that have not yet been reported in phages, including the ATP-dependent zinc metalloprotease, FtsH (gp107), and the tRNA (Ile)-lysidine synthase, TilS (gp263). The functions of these proteins in MIJ3 are unknown. In bacteria, both FtsH and Tils play important roles and are essential to the viability of the cell (Shotland et al., 2000; Soma et al., 2003; Lin et al., 2013). Therefore, it is tempting to speculate that their role in MIJ3 could be to maintain the host viability during phage replication. This can be examined by constructing FtsH and or Tils mutants and comparing the infectivity of these mutants with the wild-type phage. The amino acid sequences of $f t s H$ and tilS in MIJ3 are homologous to gp342 and gp37, respectively, of phage PA5oct, which were annotated as a structural protein and an uncharacterized protein, respectively. Further research is needed to confirm the nature and the function of these unique phage genes and proteins in MIJ3 and PA5oct.

The MIJ3 jumbo phage has several unusual genomic features, such as the GC content being drastically different from the host genome, or the presence of rare phage genes. However, MIJ3 is also unusual due to the absence of some features that were believed to be conserved across all Pseudomonas jumbo phages, such as the phage nucleus and phage spindle (Chaikeeratisak et al., 2017a). During the replication step, Pseudomonas phages 201phi2-1, phiPA3, and phiKZ can form a proteinaceous nucleus, or shell inside the host. This nucleus encloses viral DNA and enzymes involved in the DNA replication and transcription. Unlike these Pseudomonas jumbo phages, phage MIJ3 does not appear to encode the PhuZ bipolar tubulin spindle, as genome

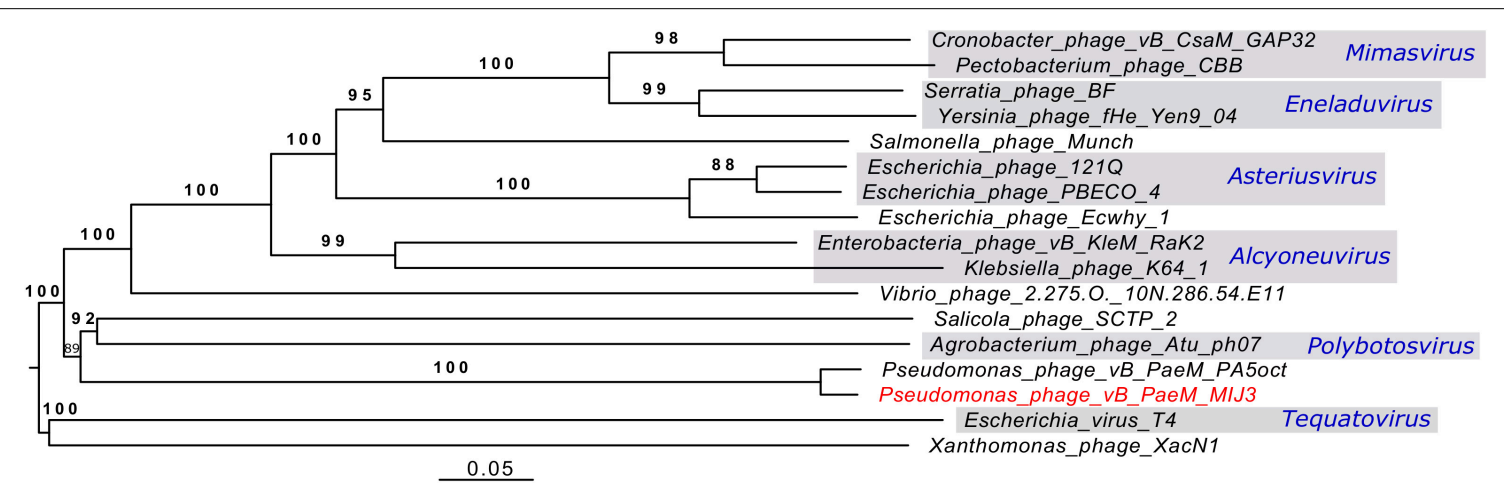

FIGURE 12 | A phylogenetic tree of phage MIJ3 and the closest phages. It shows the phylogenomic GBDP tree yielding average support of $97 \%$. The numbers above branches are GBDP pseudo-bootstrap support values from 100 replications. The branch lengths of the resulting VICTOR trees are scaled in terms of the respective distance formula used. Phage MIJ3 is marked in red color, and genus of classified phages is marked in blue. The tree was generated using the VICTOR server. 


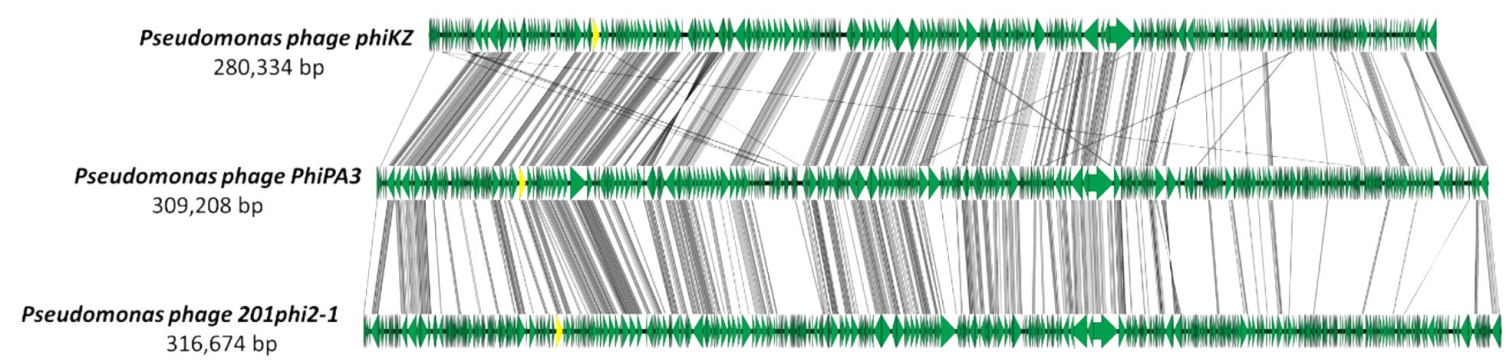

Pseudomonas phage vB_PaeM_MIJ3

288,170 bp

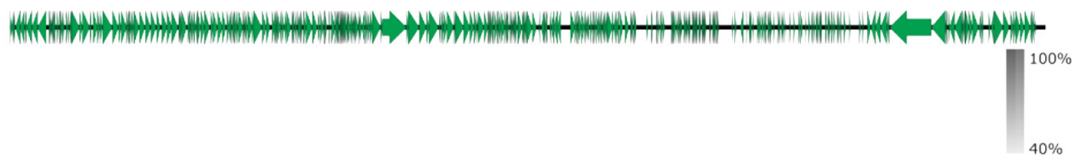

FIGURE 13 | Comparative analysis of phage MIJ3 genome with the genomes of other jumbo Pseudomonas phages phiKZ, PhiPA3, and 201phi2-1. Phage MlJ3 shows no homology to the other three phages. The yellow areas indicate the conserved genes encoding the phage nucleus and spindle tubulin in phages phiK $Z$, PhiPA3, and 201phi2-1, of which is absent in phage MlJ3.

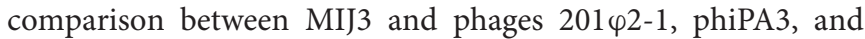
$\varphi \mathrm{KZ}$ revealed that there is no gene encoding a protein with recognizable sequence similarity to PhuZ in the sequence of phage MIJ3 (Figure 13).

MIJ3 DNA sequence is highly similar to that of another Pseudomonas phage, PA5oct (Accession Number MK797984). An earlier publication describing PA5oct suggests that its genome size is approximately $375 \mathrm{~kb}$ (Drulis-Kawa et al., 2014). However, the genomic sequence of phage PA5oct was released in April 2019 , and is in fact $287,182 \mathrm{bp}$. It is intriguing that two highly related phages were independently isolated from two geographically distant locations: phage MIJ3 (described here) was isolated from a manure sample of a domestic farm near Leicester, United Kingdom, while phage PA5oct was isolated from a sewage sample from an irrigated field near Wrocław, Poland (Drulis-Kawa et al., 2014). These findings not only suggest a wide distribution of MIJ3/PA5oct phages, but also indicate their high genomic stability.

\section{CONCLUSION}

In conclusion, this study presents analyses of the biological and genomic features of MIJ3, suggesting that phage MIJ3 and the previously identified phage PA5oct should be grouped together into a novel phage genus. In addition, phage MIJ3 has antimicrobial activity against clinical $P$. aeruginosa isolates, suggesting the potential use of this phage as a therapeutic agent.

\section{DATA AVAILABILITY STATEMENT}

Whole genome sequencing datasets generated for this study can be found in the ENA, LR588166.

\section{AUTHOR CONTRIBUTIONS}

MI carried out the main body of research, performed the bioinformatics analysis, and wrote the manuscript. BA contributed to the phage growth experiments. FP contributed to the $\mathrm{pH}$ stability and adsorption assay experiments. $\mathrm{AD}$ contributed to the AKTA purification work. NB contributed to the sequencing. AM edited the manuscript and contributed in bioinformatics analysis. MC edited the manuscript and collected the sample for phage isolation. EG supervised the work progress and edited the manuscript.

\section{FUNDING}

This work was funded by the Ministry of Education in Saudi Arabia as a Ph.D. sponsorship to MI (UMU554), the MRC Consortium grant for Medical Microbial Bioinformatics (MR/L015080/1), and EVAL-FARMS grant: Evaluating the Threat of Antimicrobial Resistance in Agricultural Manures and Slurries (NE/N019881/1).

\section{ACKNOWLEDGMENTS}

The authors thank Natalie Allcock and Anna StraatmanIwanowska for their assistance with the TEM. The authors also thank Peter Hickenbotham for his technical assistance throughout the project.

\section{SUPPLEMENTARY MATERIAL}

The Supplementary Material for this article can be found online at: https://www.frontiersin.org/articles/10.3389/fmicb.2019. 02772/full\#supplementary-material 


\section{REFERENCES}

Abbasifar, R., Griffiths, M. W., Sabour, P. M., Ackermann, H. W., Vandersteegen, K., Lavigne, R., et al. (2014). Supersize me: Cronobacter sakazakii phage GAP32. Virology 460, 138-146. doi: 10.1016/j.virol.2014.05.003

Ackermann, H., Tremblay, D., and Moineau, S. (2004). Long-term bacteriophage preservation. WFCC Newslett. 38, 35-40.

Ackermann, H. W. (2009). Basic phage electron microscopy. Methods Mol. Biol. 501, 113-126. doi: 10.1007/978-1-60327-164-6_12

Ackermann, H. W., and Nguyen, T. M. (1983). Sewage coliphages studied by electron microscopy. Appl. Environ. Microbiol. 45, 1049-1059.

Adriaenssens, E., and Brister, J. R. (2017). How to name and classify your phage: an informal guide. Viruses 9:E70. doi: 10.3390/v9040070

Ahmadi, M., Karimi Torshizi, M. A., Rahimi, S., and Dennehy, J. J. (2016). Prophylactic bacteriophage administration more effective than post-infection administration in reducing Salmonella enterica serovar Enteritidis shedding in quail. Front. Microbiol. 7:1253. doi: 10.3389/fmicb.2016.01253

Ashish, A., Shaw, M., Winstanley, C., Ledson, M. J., and Walshaw, M. J. (2012). Increasing resistance of the Liverpool Epidemic Strain (LES) of Pseudomonas aeruginosa (Psa) to antibiotics in cystic fibrosis (CF)-a cause for concern? J. Cyst. Fibros. 11, 173-179. doi: 10.1016/j.jcf.2011.11.004

Attai, H., Boon, M., Phillips, K., Noben, J., Lavigne, R., and Brown, P. J. (2018). Larger than life: isolation and genomic characterization of a jumbo phage that infects the bacterial plant pathogen, Agrobacterium tumefaciens. Front. Microbiol. 9:1861. doi: 10.3389/fmicb.2018.01861

Bieniossek, C., Schalch, T., Bumann, M., Meister, M., Meier, R., and Baumann, U. (2006). The molecular architecture of the metalloprotease FtsH. Proc. Natl. Acad. Sci. U.S.A. 103, 3066-3071. doi: 10.1073/pnas.0600031103

Bonilla, N., Rojas, M. I., Cruz, G. N. F., Hung, S., Rohwer, F., and Barr, J. J. (2016). Phage on tap-a quick and efficient protocol for the preparation of bacteriophage laboratory stocks. PeerJ 4:e2261. doi: 10.7717/peerj.2261

Briers, Y., Volckaert, G., Cornelissen, A., Lagaert, S., Michiels, C. W., Hertveldt, K., et al. (2007). Muralytic activity and modular structure of the endolysins of Pseudomonas aeruginosa bacteriophages $\varphi \mathrm{KZ}$ and EL. Mol. Microbiol. 65, 1334-1344. doi: 10.1111/j.1365-2958.2007.05870.x

Buttimer, C., Hendrix, H., Oliveira, H., Casey, A., Neve, H., McAuliffe, O., et al. (2017). Things are getting hairy: enterobacteria bacteriophage vB_PcaM_CBB. Front. Microbiol. 8:44. doi: 10.3389/fmicb.2017.00044

Cafora, M., Deflorian, G., Forti, F., Ferrari, L., Binelli, G., Briani, F., et al. (2019). Phage therapy against Pseudomonas aeruginosa infections in a cystic fibrosis zebrafish model. Sci. Rep. 9:1527. doi: 10.1038/s41598-018-37636-x

Carver, T., Harris, S. R., Berriman, M., Parkhill, J., and McQuillan, J. A. (2011). Artemis: an integrated platform for visualization and analysis of highthroughput sequence-based experimental data. Bioinformatics 28, 464-469. doi: 10.1093/bioinformatics/btr703

Casey, E., Fitzgerald, B., Mahony, J., Lugli, G. A., Ventura, M., and van Sinderen, D. (2017). Genome sequence of Serratia marcescens phage BF. Genom. Announc. 5:e0211-17. doi: 10.1128/genomeA.00211-217

Chaikeeratisak, V., Nguyen, K., Egan, M. E., Erb, M. L., Vavilina, A., and Pogliano, J. (2017a). The phage nucleus and tubulin spindle are conserved among large pseudomonas phages. Cell Rep. 20, 1563-1571. doi: 10.1016/j.celrep.2017.07.064

Chaikeeratisak, V., Nguyen, K., Khanna, K., Brilot, A. F., Erb, M. L., Coker, J. K., et al. (2017b). Assembly of a nucleus-like structure during viral replication in bacteria. Science 355, 194-197. doi: 10.1126/science.aal 2130

Chatterjee, P., Davis, E., Yu, F., James, S., Wildschutte, J. H., Wiegmann, D. D., et al. (2017). Environmental Pseudomonads inhibit cystic fibrosis patient-derived Pseudomonas aeruginosa. Appl. Environ. Microbiol. 83, e2701-e2716. doi: 10. 1128/AEM.02701-2716

Chaturongakul, S., and Ounjai, P. (2015). Phage-host interplay: examples from tailed phages and gram-negative bacterial pathogens. Front. Microbiol. 5:442. doi: 10.3389/fmicb.2014.00442

Chen, L., Yuan, S., Quan, L., Mai, G., Yang, J., Deng, D., et al. (2018). In vitro design and evaluation of phage cocktails against Aeromonas salmonicida. Front. Microbiol. 9:1476. doi: 10.3389/fmicb.2018.01476

Clokie, M. R., Millard, A. D., Letarov, A. V., and Heaphy, S. (2011). Phages in nature. Bacteriophage 1, 31-45. doi: 10.4161/bact.1.1.14942
Dassa, B., London, N., Stoddard, B. L., Schueler-Furman, O., and Pietrokovski, S. (2009). Fractured genes: a novel genomic arrangement involving new split inteins and a new homing endonuclease family. Nucleic Acids Res. 37, 25602573. doi: 10.1093/nar/gkp095

Devoto, A. E., Santini, J. M., Olm, M. R., Anantharaman, K., Munk, P., Tung, J., et al. (2019). Megaphages infect prevotella and variants are widespread in gut microbiomes. Nat. Microbiol. 4, 693-700. doi: 10.1038/s41564-018-0338-339

Donelli, G., Dore, E., Frontali, C., and Grandolfo, M. (1975). Structure and physicochemical properties of bacteriophage G: III. A homogeneous DNA of molecular weight 5× 108. J. Mol. Biol. 94, 555-565. doi: 10.1016/0022-2836(75)9032190326

Drulis-Kawa, Z., Olszak, T., Danis, K., Majkowska-Skrobek, G., and Ackermann, H. W. (2014). A giant Pseudomonas phage from Poland. Arch. Virol. 159, 567-572. doi: 10.1007/s00705-013-1844-y

Farris, J. S. (1972). Estimating phylogenetic trees from distance matrices. Am. Nat. 106, 645-668. doi: 10.1086/282802

Freestone, P. P., Hirst, R. A., Sandrini, S. M., Sharaff, F., Fry, H., Hyman, S., et al. (2012). Pseudomonas aeruginosa-catecholamine inotrope interactions: a contributory factor in the development of ventilator-associated pneumonia? Chest 142, 1200-1210. doi: 10.1378/chest.11-2614

Furfaro, L. L., Payne, M. S., and Chang, B. J. (2018). Bacteriophage therapy: clinical trials and regulatory hurdles. Front. Cell. Infect. Microbiol. 8:376. doi: 10.3389/ fcimb.2018.00376

Glonti, T., Chanishvili, N., and Taylor, P. (2010). Bacteriophage-derived enzyme that depolymerizes the alginic acid capsule associated with cystic fibrosis isolates of Pseudomonas aeruginosa. J. Appl. Microbiol. 108, 695-702. doi: 10. 1111/j.1365-2672.2009.04469.x

Göker, M., García-Blázquez, G., Voglmayr, H., Tellería, M. T., and Martín, M. P. (2009). Molecular taxonomy of phytopathogenic fungi: a case study in Peronospora. PLoS One 4:e6319. doi: 10.1371/journal.pone.0006319

Gonçalves-de-Albuquerque, C. F., Silva, A. R., Burth, P., Rocco, P. R. M., CastroFaria, M. V., and Castro-Faria-Neto, H. C. (2016). Possible mechanisms of Pseudomonas aeruginosa-associated lung disease. Int. J. Med. Microbiol. 306, 20-28. doi: 10.1016/j.ijmm.2015.11.001

Hyman, P., and Abedon, S. T. (2009). Practical methods for determining phage growth parameters. Methods Mol. Biol. 501, 175-202. doi: 10.1007/978-160327-164-6_18

Kropinski, A. M. (2009). Measurement of the rate of attachment of bacteriophage to cells. Methods Mol. Biol. 501, 151-155. doi: 10.1007/978-1-60327-164-6_15

Krylov, V. N. (2014). Bacteriophages of Pseudomonas aeruginosa: long-term prospects for use in phage therapy. Adv. Virus Res. 88, 227-278. doi: 10.1016/ B978-0-12-800098-4.00005-2

Krylov, V., Shaburova, O., Pleteneva, E., Krylov, S., Kaplan, A., Burkaltseva, M., et al. (2015). Selection of phages and conditions for the safe phage therapy against Pseudomonas aeruginosa infections. Virol. Sin. 30, 33-44. doi: 10.1007/ s12250-014-3546-3543

Kumar, S., Stecher, G., and Tamura, K. (2016). MEGA7: molecular evolutionary genetics analysis version 7.0 for bigger datasets. Mol. Biol. Evol. 33, 1870-1874. doi: 10.1093/molbev/msw054

Latz, S., Krüttgen, A., Häfner, H., Buhl, E., Ritter, K., and Horz, H. (2017). Differential effect of newly isolated phages belonging to PB1-Like, phiKZ-Like and LUZ24-Like Viruses against Multi-Drug Resistant Pseudomonas aeruginosa under varying growth conditions. Viruses 9:315. doi: 10.3390/v9110315

Lavigne, R., Ceyssens, P., and Robben, J. (2009). Phage proteomics: applications of mass spectrometry. Methods Mol. Biol. 502, 239-251. doi: 10.1007/978-160327-565-1_14

Lefort, V., Desper, R., and Gascuel, O. (2015). FastME 2.0: a comprehensive, accurate, and fast distance-based phylogeny inference program. Mol. Biol. Evol. 32, 2798-2800. doi: 10.1093/molbev/msv150

Li, D., Liu, C., Luo, R., Sadakane, K., and Lam, T. (2015). MEGAHIT: an ultra-fast single-node solution for large and complex metagenomics assembly via succinct de Bruijn graph. Bioinformatics 31, 1674-1676. doi: 10.1093/bioinformatics/ btv033

Li, D., Luo, R., Liu, C., Leung, C., Ting, H., Sadakane, K., et al. (2016). MEGAHIT v1. 0: a fast and scalable metagenome assembler driven by advanced methodologies and community practices. Methods 102, 3-11. doi: 10.1016/j. ymeth.2016.02.020 
Lin, T., Hu, Y., and Shaw, G. (2013). Two enzymes, TilS and HprT, can form a complex to function as a transcriptional activator for the cell division protease gene ftsH in Bacillus subtilis. J. Biochem. 155, 5-16. doi: 10.1093/jb/mvt081

Mazzocco, A., Waddell, T. E., Lingohr, E., and Johnson, R. P. (2009). Enumeration of bacteriophages using the small drop plaque assay system. Methods Mol. Biol. 501, 81-85. doi: 10.1007/978-1-60327-164-6_9

McNair, K., Aziz, R. K., Pusch, G. D., Overbeek, R., Dutilh, B. E., and Edwards, R. (2018). Phage genome annotation using the RAST pipeline. Methods Mol. Biol. 1681, 231-238. doi: 10.1007/978-1-4939-7343-9-17

Meier-Kolthoff, J. P., Auch, A. F., Klenk, H. P., and Göker, M. (2013). Genome sequence-based species delimitation with confidence intervals and improved distance functions. BMC Bioinformatics 14:60. doi: 10.1186/1471-2105$14-60$

Meier-Kolthoff, J. P., and Göker, M. (2017). VICTOR: genome-based phylogeny and classification of prokaryotic viruses. Bioinformatics 33, 3396-3404. doi: 10.1093/bioinformatics/btx440

Meier-Kolthoff, J. P., Hahnke, R. L., Petersen, J., Scheuner, C., Michael, V., Fiebig, et al. (2014). Complete genome sequence of DSM $30083 \mathrm{~T}$, the type strain (U5/41 T) of Escherichia coli, and a proposal for delineating subspecies in microbial taxonomy. Stand. Genom. Sci. 9:2. doi: 10.1186/1944-3277-9-2

Mesyanzhinov, V. V., Robben, J., Grymonprez, B., Kostyuchenko, V. A., Bourkaltseva, M. V., Sykilinda, N. N., et al. (2002). The genome of bacteriophage $\varphi \mathrm{KZ}$ of Pseudomonas aeruginosa. J. Mol. Biol. 317, 1-19. doi: 10.1006/jmbi.2001. 5396

Monson, R., Foulds, I., Foweraker, J., Welch, M., and Salmond, G. P. (2011). The Pseudomonas aeruginosa generalized transducing phage $\varphi \mathrm{PA} 3$ is a new member of the $\varphi \mathrm{KZ}$-like group of 'jumbo'phages, and infects model laboratory strains and clinical isolates from cystic fibrosis patients. Microbiology 157, 859-867. doi: 10.1099/mic.0.044701-44700

Morello, E., Saussereau, E., Maura, D., Huerre, M., Touqui, L., and Debarbieux, L. (2011). Pulmonary bacteriophage therapy on Pseudomonas aeruginosa cystic fibrosis strains: first steps towards treatment and prevention. PLoS One 6:e16963. doi: 10.1371/journal.pone.0016963

Nale, J. Y., Spencer, J., Hargreaves, K. R., Buckley, A. M., Trzepinski, P., Douce, G. R., et al. (2015). Bacteriophage combinations significantly reduce clostridium difficile growth in vitro and proliferation in vivo. Antimicrob. Agents Chemother. 60, 968-981. doi: 10.1128/AAC.01774-15

Pan, Y. J., Lin, T. L., Chen, C. C., Tsai, Y. T., Cheng, Y. H., Chen, Y. Y., et al. (2017). Klebsiella phage $\Phi$ K64-1 encodes multiple depolymerases for multiple host capsular types. J. Virol. 91:e2457-16. doi: 10.1128/JVI.02457-2416

Perler, F. B. (2005). Protein splicing mechanisms and applications. IUBMB Life 57, 469-476. doi: 10.1080/15216540500531739

Perler, F. B., Olsen, G. J., and Adam, E. (1997). Compilation and analysis of intein sequences. Nucleic Acids Res. 25, 1087-1093. doi: 10.1093/nar/25.6.1087

Pietrokovski, S. (1994). Conserved sequence features of inteins (protein introns) and their use in identifying new inteins and related proteins. Protein Sci. 3, 2340-2350. doi: 10.1002/pro.5560031218

Potera, C. (2013). Phage renaissance: new hope against antibiotic resistance. Environ. Health Perspect. 121, a48-a53. doi: 10.1289/ehp.121-a48

Public Health England (2019). Table 15: P. Aeruginosa Bacteraemia: Monthly Counts Split by Location of Onset by NHS Trust, from January 2018 to January 2019. GOV.UK. London: Public Health England.

Saitou, N., and Nei, M. (1987). The neighbor-joining method: a new method for reconstructing phylogenetic trees. Mol. Biol. Evol. 4, 406-425. doi: 10.1093/ oxfordjournals.molbev.a040454

Seemann, T. (2014). Prokka: rapid prokaryotic genome annotation. Bioinformatics 30, 2068-2069. doi: 10.1093/bioinformatics/btu153

Serwer, P., Hayes, S. J., Thomas, J. A., and Hardies, S. C. (2007). Propagating the missing bacteriophages: a large bacteriophage in a new class. Virol. J. 4:21. doi: $10.1186 / 1743-422 X-4-21$
Shaburova, O. V., Hertveldt, K., Krylov, S. V., Pleteneva, E. A., Burkaltseva, M. V., Lavigne, R., et al. (2006). Comparison of new giant bacteriophages OBP and Lu11 of soil pseudomonads with bacteriophages of phiKZ-supergroup of Pseudomonas aeruginosa. Genetika 42, 1065-1074.

Shotland, Y., Shifrin, A., Ziv, T., Teff, D., Koby, S., Kobiler, O., et al. (2000). Proteolysis of bacteriophage lambda CII by Escherichia coli FtsH (HflB). J. Bacteriol. 182, 3111-3116. doi: 10.1128/jb.182.11.3111-3116.2000

Šimoliūnas, E., Kaliniene, L., Truncaitè, L., Zajančkauskaitė, A., Staniulis, J., Kaupinis, et al. (2013). Klebsiella phage vB_KleM-RaK2-A giant singleton virus of the family myoviridae. PLoS One 8:e60717. doi: 10.1371/journal.pone. 0060717

Soma, A., Ikeuchi, Y., Kanemasa, S., Kobayashi, K., Ogasawara, N., Ote, T., et al. (2003). An RNA-modifying enzyme that governs both the codon and amino acid specificities of isoleucine tRNA. Mol. Cell. 12, 689-698. doi: 10.1016/ s1097-2765(03)00346-0

Sullivan, M. J., Petty, N. K., and Beatson, S. A. (2011). Easyfig: a genome comparison visualizer. Bioinformatics 27, 1009-1010. doi: 10.1093/bioinformatics/ btr039

Suttle, C. A. (2005). Viruses in the sea. Nature 437:356. doi: 10.1038/nature04160

Suzuki, T., and Miyauchi, K. (2010). Discovery and characterization of tRNAIle lysidine synthetase (TilS). FEBS Lett. 584, 272-277. doi: 10.1016/j.febslet.2009. 11.085

Sykilinda, N. N., Bondar, A. A., Gorshkova, A. S., Kurochkina, L. P., Kulikov, E. E., Shneider, M. M., et al. (2014). Complete genome sequence of the novel giant Pseudomonas phage PaBG. Genome Announc. 2:e929-13. doi: 10.1128/ genomeA.00929-913

Thomas, J. A., Rolando, M. R., Carroll, C. A., Shen, P. S., Belnap, D. M., Weintraub, S. T., et al. (2008). Characterization of Pseudomonas chlororaphis myovirus 201\$2-1 via genomic sequencing, mass spectrometry, and electron microscopy. Virology 376, 330-338. doi: 10.1016/j.virol.2008.04.004

Vandenheuvel, D., Rombouts, S., and Adriaenssens, E. M. (2018). Purification of bacteriophages using anion-exchange chromatography. Methods Mol. Biol. 1681, 59-69. doi: 10.1007/978-1-4939-7343-9_5

Waters, E. M., Neill, D. R., Kaman, B., Sahota, J. S., Clokie, M. R. J., Winstanley, C., et al. (2017). Phage therapy is highly effective against chronic lung infections with Pseudomonas aeruginosa. Thorax 72, 666-667. doi: 10.1136/thoraxjnl2016-209265

Winstanley, C., Langille, M. G., Fothergill, J. L., Kukavica-Ibrulj, I., Paradis-Bleau, C., Sanschagrin, F., et al. (2009). Newly introduced genomic prophage islands are critical determinants of in vivo competitiveness in the Liverpool Epidemic Strain of Pseudomonas aeruginosa. Genome Res. 19, 12-23. doi: 10.1101/gr. 086082.108

Yoshikawa, G., Askora, A., Blanc-Mathieu, R., Kawasaki, T., Li, Y., Nakano, M., et al. (2018). Xanthomonas citri jumbo phage XacN1 exhibits a wide host range and high complement of tRNA genes. Sci. Rep. 8:4486. doi: 10.1038/s41598018-22239-3

Yuan, Y., and Gao, M. (2017). Jumbo bacteriophages: an overview. Front. Microbiol. 8:403. doi: 10.3389/fmicb.2017.00403

Conflict of Interest: The authors declare that the research was conducted in the absence of any commercial or financial relationships that could be construed as a potential conflict of interest.

Copyright (c) 2019 Imam, Alrashid, Patel, Dowah, Brown, Millard, Clokie and Galyov. This is an open-access article distributed under the terms of the Creative Commons Attribution License (CC BY). The use, distribution or reproduction in other forums is permitted, provided the original author(s) and the copyright owner(s) are credited and that the original publication in this journal is cited, in accordance with accepted academic practice. No use, distribution or reproduction is permitted which does not comply with these terms. 